\title{
Size-dependent predation on post-settlement winter flounder Pseudopleuronectes americanus by sand shrimp Crangon septemspinosa
}

\author{
David L. Taylor* \\ Graduate School of Oceanography, University of Rhode Island, South Ferry Road, Narragansett, Rhode Island 02882, USA
}

\begin{abstract}
Juvenile flatfish that are large-at-age are assumed to have a survival advantage because of a reduction in predator-induced mortality (bigger-is-better hypothesis), but this generalization is largely unsubstantiated in fisheries research. This study examined size-dependent predation on post-settlement winter flounder Pseudopleuronectes americanus by the sand shrimp Crangon septemspinosa, and the interactive effects of flounder density and water temperature on the predator-prey interaction. Shrimp were visually observed foraging on flounder, and the major elements of the 'predation sequence' were quantified, from which the susceptibility and gross vulnerability of flounder were estimated. Flounder susceptibility generally decreased with increasing fish size until a complete refuge from shrimp predation was attained at sizes $>25 \mathrm{~mm}$ total length (TL). The gross vulnerability of flounder to shrimp predation was dome-shaped when analyzed graphically with respect to prey size. At the extremes of the vulnerability response curve, small flounder (8 to $12 \mathrm{~mm}$ TL) benefited from a decreased rate of encounters with shrimp predators, whereas large flounder (18 to $22 \mathrm{~mm}$ TL) profited from superior escape abilities and prolonged predator handling time once attacked and captured. Conversely, intermediate-sized flounder (13 to $17 \mathrm{~mm} \mathrm{TL}$ ) suffered the highest rates of mortality, and this was accentuated with increasing temperature and decreasing flounder density. Intermediate-sized flounder (17 mm TL) were the most energetically profitable for shrimp. Below this size, net energy intake of shrimp decreased because of the lower caloric content of smaller flounder. Above this size, the increased metabolic demands associated with foraging on large flounder resulted in a decrease in shrimp net-energy gain. Moreover, shrimp feeding on low densities of flounder suffered a net loss in energy intake, thus possibly explaining the observed density-dependent predation of crangonid species feeding on flatfish. Results from this study challenge the applicability of the bigger-is-better hypothesis to this specific predator-prey interaction.
\end{abstract}

KEY WORDS: Pseudopleuronectes americanus $\cdot$ Crangon septemspinosa $\cdot$ Winter flounder · Sand shrimp $\cdot$ Predation sequence $\cdot$ Bigger-is-better hypothesis

\section{INTRODUCTION}

Predation on the early life stages of marine fish is recognized as one of the most important factors regulating year-class formation and recruitment (Anderson 1988, Bailey \& Houde 1989). Fisheries research has therefore concentrated on identifying the characteristics of young-of-the-year (YOY) fish that affect predator-induced mortality. Several investigators, for example, have argued that relatively small variations in larval and juvenile fish growth rate, and thus sizeat-age, can cause order-of-magnitude differences in the number of individuals surviving to the next lifehistory stage (Houde 1987, Pepin 1990, Rice et al. 1993). Rapid growth of YOY fish is believed to increase survival by minimizing vulnerability to predation. This concept relies on 2 basic premises: rapid growth reduces the time interval that fish are vulnerable to predation (growth-mortality hypothesis, e.g. Ware 1975, Shepherd \& Cushing 1980, Anderson 1988), and 
fish that are large-at-age are less vulnerable to predation than smaller individuals (bigger-is-better hypothesis, e.g. Miller et al. 1988). Despite approaching the status of a paradigm, this latter generalization is largely unsubstantiated in fisheries research.

The premise that the vulnerability of fish to predation decreases with advanced developmental state has been criticized in recent years (Bailey \& Houde 1989, Litvak \& Leggett 1992, Fuiman \& Magurran 1994, Leggett \& DeBlois 1994, Cowan et al. 1997). The majority of studies supporting the bigger-is-better hypothesis are confounded because they concentrate exclusively on predator capture success (Fuiman \& Magurran 1994). Nevertheless, results of predation trials demonstrating that larger fish have a lower probability of being captured are routinely extrapolated to assume that larger individuals have a higher probability of survival. The gross vulnerability of fish to predation, however, is the product of 4 probabilities that constitute the 'predation sequence' - the probability of being encountered, attacked, captured, and ingested (modified from Fuiman 1989). Examining any of the individual components of the predation sequence in isolation does not warrant generalizations regarding the vulnerability of YOY fish to predation (Litvak \& Leggett 1992, Fuiman \& Magurran 1994, Cowan et al. 1997).

Bailey \& Houde (1989) proposed a series of conceptual models suggesting that larval fish, preyed upon by various predator types, exhibit gross vulnerability curves that are dome-shaped when analyzed with respect to fish size. The mechanism underlying the dome-shaped response was the counteracting effects of prey body size on the individual components of the predation sequence. Large fish generally have increased encounter rates with potential predators because they are more conspicuous and active than smaller prey (Pittman et al. 1989, 1990, Pepin et al. 1992). Conversely, rates of successful captures typically decrease with increasing prey size because large fish have greater escape swimming speeds and responsiveness to predatory attacks (Fuiman 1989, Blaxter \& Fuiman 1990, Williams \& Brown 1992). Subsequent studies analyzing size-dependent predation on early-stage marine and freshwater fish have confirmed that the product of the predation sequence generates a dome-shaped vulnerability curve (Fuiman 1989, Cowan \& Houde 1992, Litvak \& Leggett 1992, Pepin et al. 1992, Cowan et al. 1996, Lundvall et al. 1999). Despite the valuable contributions provided by these previous studies, most of the research was limited to the larval stages of fish, presumably because of the high rates of mortality suffered during this life period. For various species of flatfish, however, there is increasing evidence that survival during juvenile stages is a major determinant of year-class strength and recruitment success (Chambers et al. 1988, Bailey 1994). Yet little is known about size-dependent predation of post-settlement flatfish, and more specifically, the effect of size-selective processes on the individual components of the predation sequence.

Predation by crangonid shrimp Crangon spp. is a source of high mortality for newly settled flatfish, and thus possibly affects fish year-class strength (Van der Veer \& Bergman 1987, Seikai et al. 1993, Witting \& Able 1995). In nursery areas of the North Sea and western Wadden Sea, for example, brown shrimp $C$. crangon are important predators of juvenile plaice Pleuronectes platessa and flounder Platichthys flesus, during and shortly after the flatfish settle on tidal flats (Van der Veer \& Bergman 1987, Van der Veer et al. 1991). Similarly, the sand shrimp C. septemspinosa has been implicated as one of the most significant sources of mortality for recently settled winter flounder (Witting \& Able 1995, Taylor \& Collie 2003b, this issue).

The winter flounder Pseudopleuronectes americanus Walbaum is a medium-sized, pleuronectid flatfish inhabiting temperate estuaries of the northwest and mid-Atlantic. Spawning of demersal eggs occurs in estuaries during the winter and early spring (Pearcy 1962). After hatching, larval flounder are pelagic for approximately 60 d (Chambers \& Leggett 1987), after which the larvae metamorphose into juveniles and settle to the benthos (Pearcy 1962). The small size of recently settled winter flounder (8 to $9 \mathrm{~mm}$ total length, TL; Chambers \& Leggett 1987) and their relatively weak swimming and burying capabilities make this species particularly vulnerable to a host of crustacean and demersal fish predators (Witting \& Able 1995, Manderson et al. 1999, 2000, Fairchild \& Howell 2000). Previous laboratory experiments have examined the size-dependent mortality of larval and juvenile winter flounder to Crangon septemspinosa predation. Bertram \& Leggett (1994), for example, determined that variations in age and size of metamorphosing flounder had no effect on vulnerability to sand shrimp predation. These feeding trials were limited, however, because they concentrated on only a very brief period of the flounder's life history, and neglected to examine the susceptibility to shrimp predation throughout the entire mortality window. In the examination of predator-induced mortality throughout the larval and early juvenile period of winter flounder, Witting \& Able (1995) modeled the flounder's predator-prey interaction with sand shrimp using a conceptual approach based on assumptions that (1) shrimp encounter rates with flounder change as a function of the fish's spatial distribution (pelagic versus benthic); and (2) the likelihood of successful captures following an encounter decreases with increasing flounder size. The model 
predicted that flounder vulnerability to shrimp predation is maximal precisely at initial settlement, then decreases dramatically until a complete refuge from $C$. septemspinosa predation is attained once flounder grow to $24 \mathrm{~mm}$ TL. The failure of the model to incorporate size-dependent encounter rates for postsettlement (benthic) flounder, however, potentially overestimates predation on small juvenile flounder, and underestimates mortality for larger individuals, assuming that shrimp encounters with juvenile flounder increase with increasing fish size (Pittman et al. 1989, 1990, Pepin et al. 1992).

The interactive effects of other abiotic and biotic parameters are likely to influence the size-dependent predation of Crangon septemspinosa upon juvenile winter flounder. Taylor \& Collie (2003b) examined the joint effects of varying flounder density and temperature on shrimp foraging behavior and flounder mortality. Shrimp foraging at $10^{\circ} \mathrm{C}$ exhibited a sigmoidal, Type III functional response to varying densities of flounder, whereas a hyperbolic, Type II response best characterized shrimp-feeding behavior at $16^{\circ} \mathrm{C}$. The variable functional responses observed across temperatures was attributed to greater predator activity at warmer temperatures, which in turn increased the number of encounters and captures of juvenile flounder (Taylor \& Collie 2003b). This earlier experiment only examined the combined effect of temperature and flounder density on sand shrimp feeding behavior and flounder mortality, thereby precluding possible confounding effects of prey size on the predator-prey interaction.

The purpose of the following investigation was to determine whether Crangon septemspinosa predation on post-settlement winter flounder is size-dependent during the early juvenile period. Moreover, the interactive effects of flounder density and water temperature on size-dependent predation were analyzed. The specific objectives were (1) to determine, through visual observations, the rates of shrimp encounters, attacks, captures, and ingestion of flounder as a function of prey size and density, as well as temperature; (2) to quantify other predatory behaviors (i.e. prey recognition, attack success, capture success, and handling time) that potentially affect the size-dependent predation on flounder; (3) to predict the susceptibility and gross vulnerability of flounder to shrimp predation derived from empirical estimates of the complete predation sequence; (4) to estimate prey profitability (i.e. shrimp gross and net caloric ingestion rate) as a function of flounder size; and (5) to compare results from this study with those predicted from the existing paradigm that being large in size increases juvenile flatfish survival, and thus, test the validity of the biggeris-better hypothesis.

\section{MATERIALS AND METHODS}

Collection and maintenance of experimental animals. Juvenile winter flounder were provided by Llennoco Inc. (Chatham, MA, USA). All flounder were maintained in $39 \mathrm{l}$ aquaria that were immersed in an ambient temperature flow-through seawater bath (6 to $12^{\circ} \mathrm{C}$ ), and fed wild plankton consisting primarily of copepod nauplli, rotifers, and polychaete larvae. Prior to experiments, flounder were measured to the nearest $\mathrm{mm}$ with calipers. Only those fish measuring 8 to $22 \mathrm{~mm}$ TL were used in experiments. Experimental flounder body sizes constitute the range over which flounder are vulnerable to sand shrimp predation (Witting \& Able 1995).

Adult Crangon septemspinosa were collected with beam trawls from the Niantic River (Connecticut, USA). Shrimp were then transferred to the laboratory where they were maintained in large flow-through tanks and fed frozen clam ad libitum each day. Only adult shrimp measuring 45 to $65 \mathrm{~mm}$ TL from the tip of the antennal scale to the end of the telson were used during this investigation. This size class dominates northern-temperate estuaries during late spring and early summer (Price 1962), and shrimp of this size have been observed to readily consume juvenile winter flounder (Witting \& Able 1995).

Visual observations. Adult sand shrimp were observed feeding on varying size classes of juvenile winter flounder to test for the presence of size-dependent predation. Three flounder sizes classes were examined: small ( 8 to $12 \mathrm{~mm} \mathrm{TL}$ ), medium (13 to $17 \mathrm{~mm} \mathrm{TL}$ ), and large (18 to $22 \mathrm{~mm} \mathrm{TL}$ ). Interactions between shrimp and flounder were recorded with a monochrome video camera connected to a video recorder. Filming was performed continuously for $8 \mathrm{~h}$ under darkness, with illumination provided by infrared-emitting diodes, thus achieving higher contrast on the video recording. Feeding observations performed under darkness simulated the shrimp's natural tendency for nocturnal foraging (Wilcox \& Jeffries 1974). The experimental filming arena $(4.0 \mathrm{~cm}$ high, $40.0 \mathrm{~cm}$ diameter $)$ was immersed in a temperature-controlled water bath $\left( \pm 1.0^{\circ} \mathrm{C}\right)$. Two water temperatures were implemented in this experiment: 10.0 and $16.0^{\circ} \mathrm{C}$. Experimental temperatures represent (1) late spring to early summer average temperature found in northern-temperate estuaries $\left(10.0^{\circ} \mathrm{C}\right)(\mathrm{DNC} 2003)$; and (2) higher temperatures simulating anomalous warm years (DNC 2003) and possible future conditions resulting from anthropogenic impacts on global climate $\left(16.0^{\circ} \mathrm{C}\right.$ ) (Schuurmans 1995). Two densities of flounder (2 and 10 fish per tank; 15.9 and 79.6 fish $\mathrm{m}^{-2}$ ) were exposed to 2 adult shrimp (15.9 shrimp m${ }^{-2}$ ) measuring 45 to $65 \mathrm{~mm}$ TL. The densities of flounder in this study are at, or be- 
yond, natural densities of flatfish found in field populations (Meise et al. 1999, Sogard et al. 2001). Experimental flounder densities were chosen, however, to ensure encounters between predators and prey were sufficiently frequent for statistical comparisons across treatments, and to maintain consistency with previous investigations that examined size-dependent mortality of metamorphosed flounder to sand shrimp predation (Bertram \& Leggett 1994). Shrimp densities in this study represent a moderate range found in northerntemperate estuaries (Price 1962). Differences in shrimp size among experimental trials were not accounted for so that flounder mortality could be evaluated without the confounding effects of changing predator size. Alternatively, it was assumed that each shrimp had the same probability of successfully consuming a givensized flounder (Gibson et al. 1995).

Before the onset of any behavioral observations, shrimp and flounder were acclimated to experimental conditions (temperature $=10.0$ or $16.0^{\circ} \mathrm{C}$ ) for at least $48 \mathrm{~h}$. Shrimp were starved $24 \mathrm{~h}$ prior to filming to standardize hunger levels across treatments, and therefore avoid possible biases as a result of predator condition. Flounder were fed a diet of wild plankton continually throughout the investigation. Shrimp were introduced into the filming arena at least $3 \mathrm{~h}$ before observations began. Subsequently, flounder of a specific density ( 2 or 10 fish per tank) and from 1 of the 3 experimental size classes (small, medium, or large) were introduced into the filming arena at 18:00 h, after which point filming began. Five to 6 replicate $8 \mathrm{~h}$ filming episodes were performed for each treatment combination (flounder size, density, and temperature), from which the following predatory behaviors were quantified:

(1) Encounter rate $(E)$ (no. encounters $8 \mathrm{~h}^{-1}$ ): any physical contact between shrimp and flounder that resulted in a noticeable reaction from the predator and/or prey;

(2) Attack rate $(A)$ (no. attacks $8 \mathrm{~h}^{-1}$ ): the intentional physical contact between shrimp and flounder that resulted from a discernable predatory strike;

(3) Capture rate $(C)$ (no. captures $8 \mathrm{~h}^{-1}$ ): the total number of attacks that resulted in shrimp seizing and maintaining initial control of a flounder;

(4) Ingestion rate $(I)$ (no. ingested $8 \mathrm{~h}^{-1}$ ): the total number of captures that resulted in the consumption of a flounder;

(5) Prey recognition (R): proportion of shrimp encounters with flounder that resulted in a predator attack $(A / E)$;

(6) Attack success $\left(S_{\mathrm{A}}\right)$ : proportion of shrimp attacks on flounder that resulted in a capture of the prey $(C / A)$;

(7) Capture success $\left(S_{\mathrm{C}}\right)$ : proportion of shrimp captures of flounder that resulted in a prey being ingested $(I / C)$;
(8) Handling time $\left(T_{\mathrm{h}}\right)(\mathrm{h})$ : the time from the initial encounter between shrimp and flounder, through the attack, capture, and ingestion of prey, until searching by the predator resumed.

Prey depletion was accounted for in these experiments by standardizing behavioral observations by the number of shrimp and flounder present at any given point during a trial. That is, prey density was not considered constant during a trial, and thus, calculations accounted for the removal of flounder due to shrimp predation. Results were analyzed with a 3-way analysis of variance (ANOVA) model using flounder size, density, and water temperature as fixed factors. Data represented as proportions were arc-sin square-root transformed to meet assumptions of normality and homogeneity of variance. The mean values of the quantified shrimp-feeding behaviors across 3 levels of flounder size were contrasted with Ryan-EinotGabriel-Welsch (Ryan's Q) multiple comparison test (Day \& Quinn 1989).

Predation sequence, susceptibility and vulnerability. Visual observations of predator behavior provided estimates of the individual components of the complete predation sequence. In this study, the predation sequence was defined by the following components:

(1) Encounters $\left(E^{\prime}\right)$ : number of shrimp encounters with flounder per unit area per unit time (no. encounters shrimp ${ }^{-1} \mathrm{~m}^{-2} \mathrm{~h}^{-1}$ );

(2) Attack probability $\left(P_{\mathrm{A}}\right)$ : probability of a shrimp attacking a flounder given an encounter;

(3) Capture probability $\left(P_{\mathrm{C}}\right)$ : probability of a shrimp capturing a flounder given an attack;

(4) Ingestion probability $\left(P_{\mathrm{I}}\right)$ : probability of a shrimp ingesting a flounder given a capture.

Shrimp encounters $\left(E^{\prime}\right)$ with flounder were analyzed with a multiple linear regression to provide encounter estimates as a continuous function of flounder size, density, and temperature. Thus, $E^{\prime}$ was estimated from 3 levels of flounder size $(10,15,20 \mathrm{~mm}$ TL = mean body length used in a given size-class), and 2 levels of flounder density ( 2 and 10 fish per tank) and temperature $\left(10\right.$ and $\left.16^{\circ} \mathrm{C}\right)$. The remaining components of the predation sequence, i.e. attacks $(A)$, captures $(C)$, and ingestion $(I)$, were recalculated as conditional probabilities $\left(P_{\mathrm{A}}, P_{\mathrm{C}}\right.$ and $P_{\mathrm{I}}$, respectively) using a logistic regression analysis employing a method of maximum likelihood. The natural logarithm of the ratio of response frequencies (Logits) was used to estimate parameters of a linear model. A given probability $(P)$ was equal to:

$$
P=\frac{\mathrm{e}^{\text {Logit }(P)}}{1+\mathrm{e}^{\operatorname{Logit}(P)}}
$$

and $\operatorname{Logit}(P)$ was equal to:

$$
\text { Logit }(P)=\alpha+\beta_{1} \mathrm{TL}+\beta_{2} \rho_{\mathrm{f}}+\beta_{3} T+\varepsilon
$$


where $\alpha$ is the intercept parameter, $\beta_{1,2,3}$ are the vectors of slope parameters, TL is the body size, or total length, of flounder $(\mathrm{mm}), \rho_{\mathrm{f}}$ is flounder density (no. fish $\left.\mathrm{m}^{-2}\right), T$ is water temperature $\left({ }^{\circ} \mathrm{C}\right)$, and $\varepsilon$ are potential interaction effects between explanatory variables. The data used to generate the probability statements were treated as frequency responses (event or no event) rather than continuous responses, and thus, a chisquare value was calculated to test for the significance of treatment variables (flounder size, density, and temperature).

Flounder susceptibility and gross vulnerability to shrimp predation were predicted from the estimated components of the complete predation sequence. Accordingly, susceptibility $(S)$ :

$$
S=P_{\mathrm{A}} \times P_{\mathrm{C}} \times P_{\mathrm{I}}
$$

and gross vulnerability $\left(G_{\mathrm{V}}\right)$ :

$$
G_{\mathrm{V}}=\left(E^{\prime} \times P_{\mathrm{A}} \times P_{\mathrm{C}} \times P_{\mathrm{I}}\right) \times F
$$

where $E^{\prime}, P_{\mathrm{A}}, P_{\mathrm{C}}$ and $P_{\mathrm{I}}$ represent the components of the predation sequence discussed above, and $F$ is the feeding period of shrimp (h) over a $24 \mathrm{~h}$ period. Because of the shrimp's tendency for nocturnal foraging, $F$ was calculated as the total time of darkness in a complete daily cycle $(10 \mathrm{~h})$. Thus, $G_{\mathrm{V}}$ is the number of flounder eaten shrimp $\mathrm{p}^{-1} \mathrm{~m}^{-2} \mathrm{~d}^{-1}$.

Gross and net caloric intake. Predator ingestion rates were used to calculate the gross caloric intake by shrimp to determine whether their feeding intensity on juvenile flatfish was sufficient to provide enough energy to compensate for basic biological demands (i.e. metabolic rates). The total mass of flounder consumed ( $g$ wet wt eaten shrimp ${ }^{-1} 8 \mathrm{~h}^{-1}$ ) was estimated by multiplying the number of prey ingested (no. fish eaten shrimp ${ }^{-1} 8 \mathrm{~h}^{-1}$ ) by the mass of a juvenile flounder whose length was equal to the mean body length used in a given size-class $($ small $=10 \mathrm{~mm} \mathrm{TL}$, medium $=$ $15 \mathrm{~mm} \mathrm{TL}$, and large $=20 \mathrm{~mm} \mathrm{TL}$ ). The mean length ( $\mathrm{TL}_{i} \mathrm{~mm}$ ) of a flounder was converted to weight $(\mathrm{mg})$ based on the following length-weight relationship (Rose et al. 1996):

$$
W_{\mathrm{d}}=\left(\frac{\mathrm{TL}}{10.723}\right)^{\frac{1}{0.28}}
$$

where $W_{\mathrm{d}}$ is flounder weight measured as mg dry weight. This was converted to wet weight ( $W_{\text {wi }} g$ ) by assuming that water constitutes $80 \%$ of the total wet weight (Schreiber \& Specker 1999) and dividing by 1000 to convert from milligrams to grams.

Shrimp ingestion rate, measured as total mass eaten (g wet wt eaten shrimp ${ }^{-1} 8 \mathrm{~h}^{-1}$ ), was expressed as caloric energy intake by multiplying the total mass eaten by the energy content of juvenile flounder. The energy content of flounder was estimated from the linear relationship presented by Kitchell et al. (1977):

$$
C=\left(5.537-0.059 \times P_{\mathrm{w}}\right) \times 1000
$$

where $C$ is the caloric content of fish (cal g wet wt ${ }^{-1}$ ) and $P_{\mathrm{w}}$ represents the percent water of wet weight $(80 \%)$. The gross energy intake by shrimp over the observation period was therefore expressed as calories eaten shrimp $\mathrm{p}^{-1} 8 \mathrm{~h}^{-1}$.

The net energy intake of shrimp was calculated by subtracting the metabolic costs of the predator (active and routine respiration) from the gross caloric intake. Previous laboratory experiments examining the size and temperature-dependent metabolic rate (oxygen consumption) of Crangon septemspinosa determined that an adult shrimp (50 $\mathrm{mm}$ TL and approximately $1 \mathrm{~g}$ wet wt) consumes $0.134 \mathrm{mg} \mathrm{O}_{2} \mathrm{~h}^{-1}$ at $10^{\circ} \mathrm{C}$ and $0.256 \mathrm{mg} \mathrm{O}_{2} \mathrm{~h}^{-1}$ at $16^{\circ} \mathrm{C}$ during routine respiration, and $0.264 \mathrm{mg} \mathrm{O}_{2} \mathrm{~h}^{-1}$ at $10^{\circ} \mathrm{C}$ and $0.437 \mathrm{mg} \mathrm{O}_{2} \mathrm{~h}^{-1}$ at $16^{\circ} \mathrm{C}$ during active respiration (Taylor \& Peck in press). The values for routine and active oxygen uptake by shrimp were converted to caloric energy units based on the following relationship: for ammoniotelic organisms, $1 \mathrm{mg} \mathrm{O}_{2}$ consumed liberates $3.20 \mathrm{cal}$ (Elliott \& Davison 1975). Accordingly, respiration at 10 and $16^{\circ} \mathrm{C}$ yielded an energy output of 0.430 and $0.829 \mathrm{cal} \mathrm{shrimp}^{-1} \mathrm{~h}^{-1}$ (routine), and 0.843 and $1.398 \mathrm{cal} \mathrm{shrimp}^{-1} \mathrm{~h}^{-1}$ (active). Total metabolic expenditure is the sum of the energy loss due to routine and active respiration. Routine respiration is the metabolic rate of quiescent individuals, plus additional metabolic costs accounting for brief periods of spontaneous activity. Conversely, active respiration is the minimum amount of oxygen consumption during maximum sustained activity. Shrimp were assumed to actively respire during the handling of flounder prey. Conversely, routine respiration characterized shrimp that were not engaged with flounder.

The total time that individual shrimp spent handling flounder $(\mathrm{h})$ during a complete filming episode $(8 \mathrm{~h})$ was multiplied by the active respiration ( 0.843 and 1.398 cal shrimp ${ }^{-1} \mathrm{~h}^{-1}$ at 10 and $16^{\circ} \mathrm{C}$, respectively). The remaining time of the observation period $(8 \mathrm{~h}$ minus total handling time) was multiplied by the shrimp's routine respiration $(0.430$ and 0.829 cal shrimp ${ }^{-1} \mathrm{~h}^{-1}$ at 10 and $16^{\circ} \mathrm{C}$, respectively). Total shrimp metabolic expenditure during an experimental trial was calculated as the sum of the estimated energy loss from both active and routine respiration (total metabolic loss $=$ active + routine respiration cal shrimp $^{-1}$ $8 \mathrm{~h}^{-1}$ ). The net energetic ingestion rate for shrimp was calculated as the gross caloric intake minus total metabolic losses.

Gross and net caloric ingestion rates of shrimp were analyzed with a 3-way ANOVA model using flounder size, density, and water temperature as fixed factors. 
The mean values of caloric intake across 3 levels of flounder size were contrasted with Ryan's $Q$ multiplecomparison test.

A theoretical maximum caloric intake by shrimp was estimated as a function of flounder size. The caloric content of flounder between 8 and $22 \mathrm{~mm}$ TL was calculated as described above. To estimate maximum theoretical gross caloric intake, shrimp were assumed to feed continuously on flounder during an $8 \mathrm{~h}$ period (i.e. no prey-density constraints). Shrimp maximum consumption rates were constrained by (1) flounder sizespecific handling time $\left(T_{\mathrm{h}}\right)$, and (2) the fact that the volume of flounder eaten every $2 \mathrm{~h}$ could not exceed the stomach volume of shrimp (Gibson et al. 1995). The maximum net caloric intake was calculated as the gross intake minus losses due to shrimp metabolic activity. Because shrimp were assumed to feed continuously, metabolic loss was defined as the total amount of calories liberated due to active respiration only (average active respiration at 10 and $16^{\circ} \mathrm{C}=8.97 \mathrm{cal}$ shrimp $^{-1} 8 \mathrm{~h}^{-1}$ ).

Shrimp theoretical maximum energy intake was compared to predicted caloric ingestion rates (cal eaten shrimp $\mathrm{p}^{-1} 8 \mathrm{~h}^{-1}$ ) over a continuous range of flounder size (8 to $22 \mathrm{~mm} \mathrm{TL}$ ): (1) to determine the feeding efficiency of shrimp preying on flounder; and (2) to determine whether or not shrimp consume sizespecific flounder at rates that maximize net energetic gain. Predicted caloric ingestion rates (cal eaten shrimp ${ }^{-1} 8 \mathrm{~h}^{-1}$ ) were estimated from the gross vulnerability of flounder to shrimp predation, as presented in Eq. (4). The feeding period of shrimp $(F)$, however, was defined as $8 \mathrm{~h}$ (as opposed to $10 \mathrm{~h}$ ). The predicted number of flounder consumed over the $8 \mathrm{~h}$ period was converted to net energy intake as described above (net intake $=$ gross intake - metabolic loss). The final predicted caloric ingestion rate of shrimp (cal eaten shrimp ${ }^{-1} 8 \mathrm{~h}^{-1}$ ) was estimated from the average of the net energy intake calculated for each temperature and density treatment combination (temperature $=10$ or $16^{\circ} \mathrm{C}$; density $=2$ or 10 flounder per tank).

\section{RESULTS}

\section{Visual observations}

Small juvenile flounder experienced significantly fewer encounters $(E)$ with predatory shrimp as compared to medium or large flounder (Table 1, Fig. 1a,b). Averaged across temperature and flounder-density treatments, a small flounder ( 8 to $12 \mathrm{~mm}$ TL) experienced $11.2 \pm 2.3$ encounters with an individual shrimp over the specified feeding period $(8 \mathrm{~h})$. Increasing flounder body length to a medium (13 to $17 \mathrm{~mm} \mathrm{TL}$ ) or large (18 to $22 \mathrm{~mm} \mathrm{TL}$ ) size, however, resulted in a

Table 1. Crangon septemspinosa predation on Pseudopleuronectes americanus. Summary statistics for ANOVA of the effects of flounder size ( $\mathrm{small}=8$ to $12 \mathrm{~mm}$, medium $=13$ to $17 \mathrm{~mm}$, and large $=18$ to $22 \mathrm{~mm}$ ), flounder density ( 2 and 10 fish per tank) and temperature $\left(10\right.$ and $\left.16^{\circ} \mathrm{C}\right)$ on observed shrimp-foraging parameters. $R, S_{\mathrm{A}}$ and $S_{\mathrm{C}}$ proportions arc-sine square-root transformed

\begin{tabular}{|c|c|c|c|c|c|c|c|c|}
\hline Source & $\begin{array}{c}\text { Encounter } \\
(E)\end{array}$ & $\begin{array}{l}\text { Attack } \\
\qquad(A)\end{array}$ & $\begin{array}{c}\text { Capture } \\
\text { (C) }\end{array}$ & $\begin{array}{l}\text { Ingestion } \\
\quad(I)\end{array}$ & $\begin{array}{c}\text { Prey } \\
\text { recognition } \\
(R)\end{array}$ & $\begin{array}{c}\text { Attack } \\
\text { success } \\
\left(S_{\mathrm{A}}\right)\end{array}$ & $\begin{array}{c}\text { Capture } \\
\text { success } \\
\left(S_{\mathrm{C}}\right)\end{array}$ & $\begin{array}{c}\text { Handling } \\
\text { time } \\
\left(T_{\mathrm{h}}\right)\end{array}$ \\
\hline \multicolumn{9}{|l|}{ Density } \\
\hline$F(\mathrm{df})$ & $2.28(1)$ & $2.05(1)$ & $1.39(1)$ & $1.74(1)$ & $4.36(1)$ & $0.22(1)$ & $1.34(1)$ & $19.47(1)$ \\
\hline $\mathrm{p}$ & 0.1371 & 0.1581 & 0.2433 & 0.1929 & $<0.05$ & 0.6399 & 0.2540 & $<0.0001$ \\
\hline \multicolumn{9}{|l|}{ Size } \\
\hline$F(\mathrm{df})$ & $17.61(2)$ & $18.34(2)$ & $7.68(2)$ & $5.05(2)$ & $4.74(2)$ & $8.06(2)$ & $52.97(2)$ & $133.25(2)$ \\
\hline $\mathrm{p}$ & $<0.0001$ & $<0.0001$ & $<0.005$ & $<0.01$ & $<0.05$ & $<0.001$ & $<0.0001$ & $<0.0001$ \\
\hline \multicolumn{9}{|c|}{ Density $\times$ Size } \\
\hline$F(\mathrm{df})$ & $1.35(2)$ & $0.42(2)$ & $2.58(2)$ & $1.36(2)$ & $1.44(2)$ & $2.50(2)$ & $2.39(2)$ & $10.73(2)$ \\
\hline $\mathrm{p}$ & 0.2687 & 0.6578 & 0.0852 & 0.2644 & 0.2454 & 0.0919 & 0.1040 & $<0.0001$ \\
\hline \multicolumn{9}{|c|}{ Temperature } \\
\hline$F(\mathrm{df})$ & $2.72(1)$ & $5.03(1)$ & $3.35(1)$ & $10.84(1)$ & $10.18(1)$ & 3.59 (1) & $1.62(1)$ & $1.04(1)$ \\
\hline $\mathrm{p}$ & 0.1050 & $<0.05$ & 0.0727 & $<0.005$ & $<0.005$ & 0.0638 & 0.2100 & 0.3106 \\
\hline \multicolumn{9}{|c|}{ Density $\times$ Temperature } \\
\hline$F(\mathrm{df})$ & $3.98(1)$ & $8.49(1)$ & $6.59(1)$ & $1.93(1)$ & $2.18(1)$ & $0.47(1)$ & $0.00(1)$ & $14.31(1)$ \\
\hline $\mathrm{p}$ & 0.0510 & $<0.01$ & $<0.05$ & 0.1701 & 0.1461 & 0.4978 & 0.9531 & $<0.0005$ \\
\hline \multicolumn{9}{|c|}{ Size $\times$ Temperature } \\
\hline$F(\mathrm{df})$ & $0.63(2)$ & $1.48(2)$ & $0.62(2)$ & $1.25(2)$ & $0.26(2)$ & $1.50(2)$ & $0.23(2)$ & $0.31(2)$ \\
\hline $\mathrm{p}$ & 0.5368 & 0.2376 & 0.5417 & 0.2957 & 0.7756 & 0.2316 & 0.7963 & 0.7371 \\
\hline \multicolumn{9}{|c|}{ Density $\times$ Size $\times$ Temperature } \\
\hline$F(\mathrm{df})$ & $0.22(2)$ & $1.85(2)$ & $3.11(2)$ & $1.64(2)$ & $2.05(2)$ & $0.19(2)$ & $0.50(2)$ & $8.00(2)$ \\
\hline $\mathrm{p}$ & 0.8011 & 0.1674 & 0.0524 & 0.2043 & 0.1394 & 0.8308 & 0.6120 & $<0.001$ \\
\hline
\end{tabular}



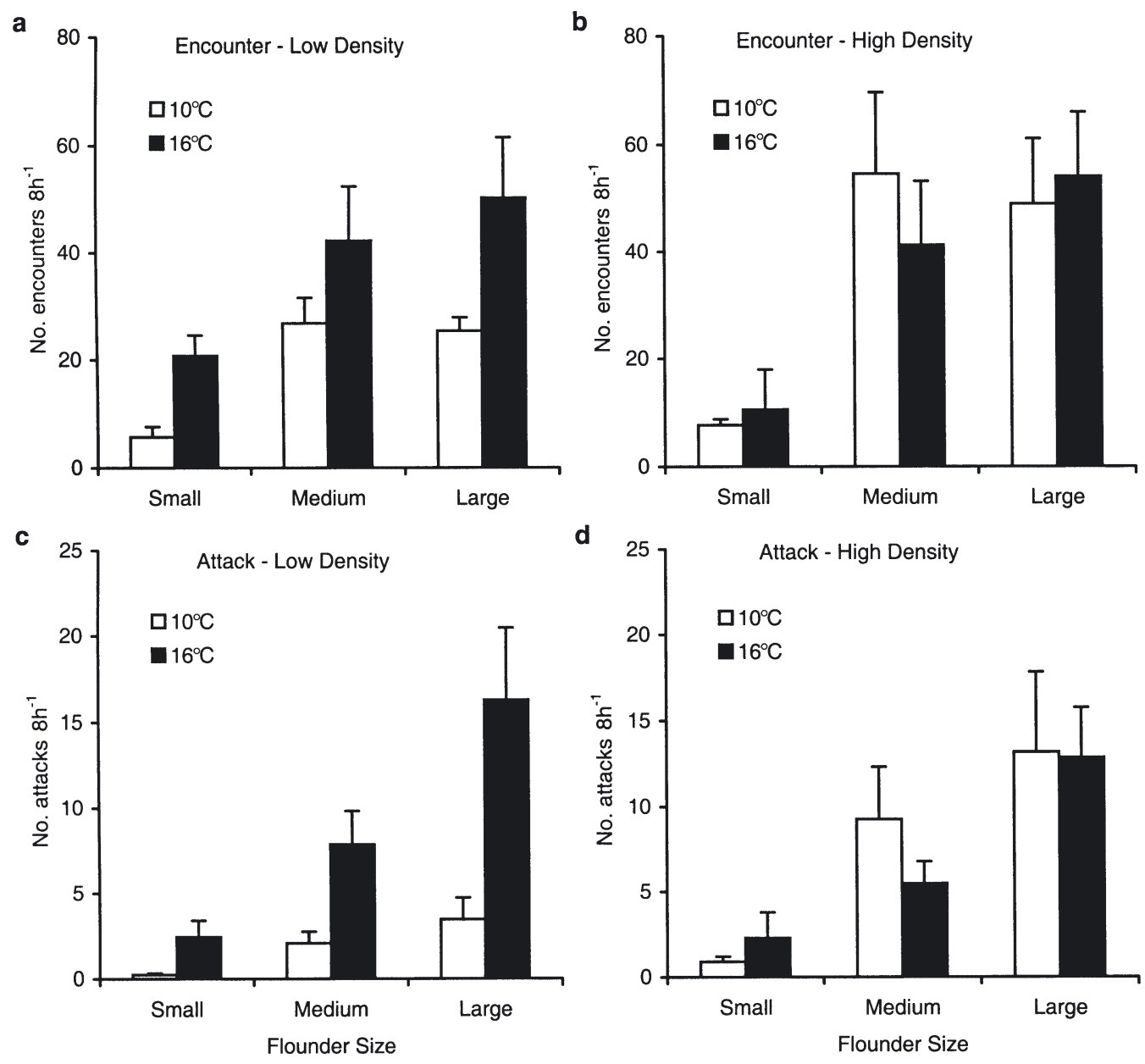

Fig. 1. Crangon septemspinosa predation on Pseudopleuronectes americanus. Observed encounters $(E)(\mathrm{a}, \mathrm{b})$ and attacks $(A)(\mathrm{c}, \mathrm{d})$ of shrimp preying on post-settlement winter flounder as a function of flounder size (small = 8 to $12 \mathrm{~mm}, \mathrm{medium}=13 \mathrm{to} 17 \mathrm{~mm}$, and large $=18$ to $22 \mathrm{~mm})$, temperature $\left(10^{\circ} \mathrm{C}=\right.$ white bars, $16^{\circ} \mathrm{C}=$ black bars) and flounder density (low density $=2$ fish per tank, high density $=10$ fish per tank). Values are means $( \pm \mathrm{SE})$. See Table 1 for significant levels

significant 3.7- to 4.0-fold increase in encounter rates. Shrimp size-dependent encounters with flounder did not differ significantly with temperature or flounder density (Table 1, Fig. 1a,b). However, the interaction effect of flounder density and temperature was nearly significant $(p=0.0510$; Table 1$)$, and was attributed to a $96 \%$ increase in encounters at $16^{\circ} \mathrm{C}$ relative to $10^{\circ} \mathrm{C}$, when shrimp were foraging at the low flounder density (Fig. 1a). Moreover, when shrimp foraged at $10^{\circ} \mathrm{C}$, flounder suffered a significant increase in encounters at high prey density relative to the low density (Fig. 1a,b).

Shrimp predatory attacks on flounder $(A)$ significantly increased with increasing flounder size-class, irrespective of temperature and flounder density (Table 1, Fig. 1c,d). A small flounder suffered an average of $1.5 \pm 0.5$ attacks shrimp ${ }^{-1} 8 \mathrm{~h}^{-1}$ during observations, whereas medium and large-sized flounder experienced $6.1 \pm 1.1$ and $11.3 \pm 1.9$ attacks shrimp ${ }^{-1} 8 \mathrm{~h}^{-1}$, respectively. Shrimp attacks also differed significantly with temperature, but not with flounder density (Table 1, Fig. 1c,d). The temperature-density interaction effect was significant, however, thereby precluding contrasts across the temperature or possible density effect (Table 1). The interaction effect between temperature and flounder density was due to a significant increase in attacks at $16^{\circ} \mathrm{C}$ compared to $10^{\circ} \mathrm{C}$, when exposed to the low flounder density, and no temperature effect on attacks when shrimp fed on the high flounder density (Fig. 1c,d). Moreover, at low temperatures, shrimp attacks decreased by $75 \%$ at the low flounder density relative to the high density (Fig. 1c,d).

The number of flounder captured by shrimp $(C)$ was significantly greater for large flounder relative to small or medium-sized fish (Table 1, Fig. 2a,b). Small and medium-sized flounder experienced a 2.9- to 5.3-fold decrease in captures relative to large flounder $($ small $=0.22 \pm 0.04$, medium $=0.40 \pm 0.07$, and 

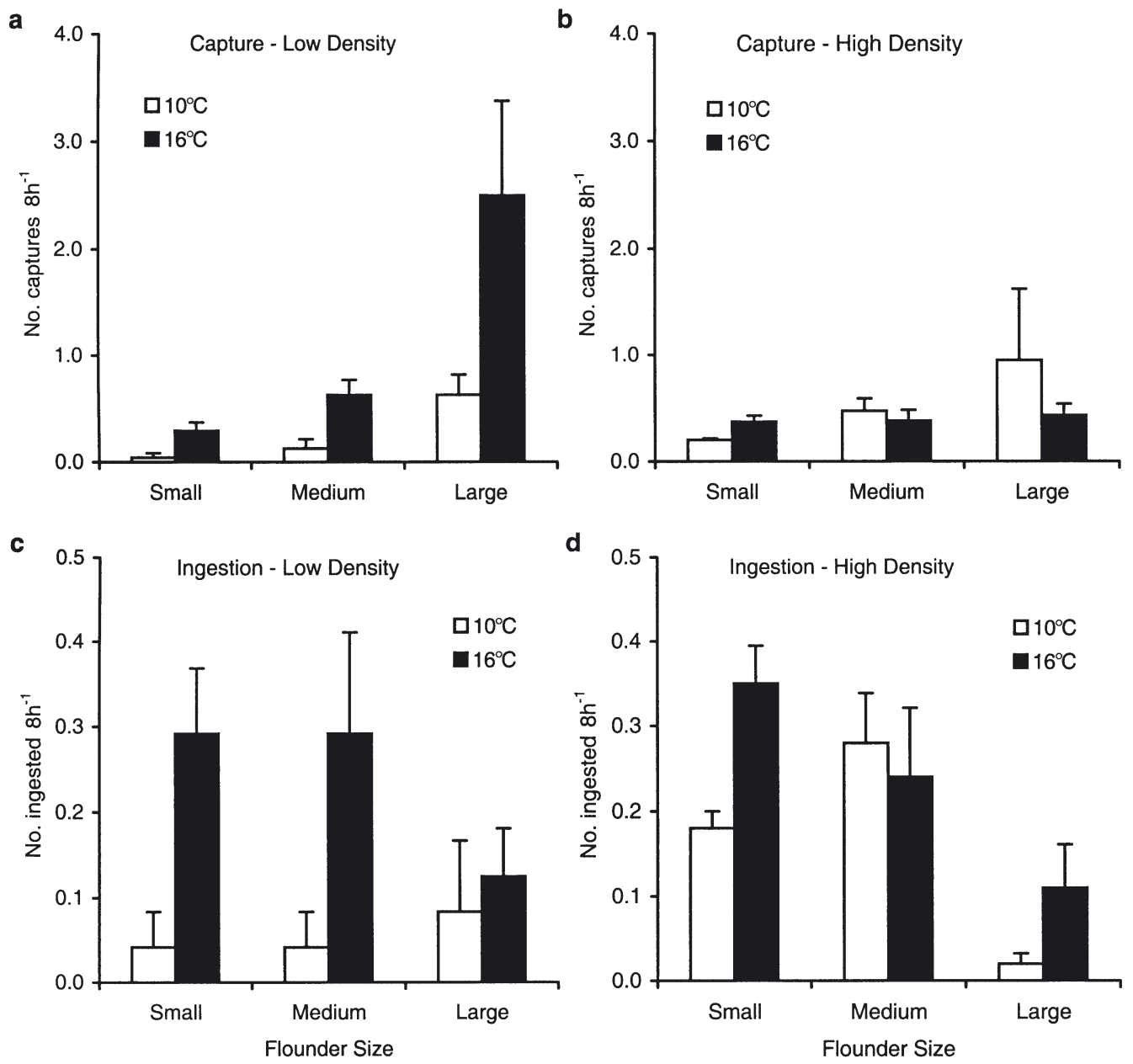

Fig. 2. Crangon septemspinosa predation on Pseudopleuronectes americanus. Observed captures $(C)(\mathrm{a}, \mathrm{b})$ and ingestion $(I)(\mathrm{c}, \mathrm{d})$ of shrimp preying on post-settlement winter flounder as a function of flounder size (small = 8 to $12 \mathrm{~mm}$, medium =13 to $17 \mathrm{~mm}$, and large $=18$ to $22 \mathrm{~mm})$, temperature $\left(10^{\circ} \mathrm{C}=\right.$ white bars, $16^{\circ} \mathrm{C}=$ black bars) and flounder density (low density $=2$ fish per tank, high density $=10$ fish per tank). Values are means $( \pm \mathrm{SE})$. See Table 1 for significant levels

large $=1.17 \pm 0.32$ captures flounder ${ }^{-1}$ shrimp $^{-1} 8 \mathrm{~h}^{-1}$ ). Shrimp size-dependent captures of flounder were independent of temperature and flounder density (Table 1). As observed with encounters $(E)$ and attacks (A), however, the temperature-density interaction term was significant (Table 1), and was attributed to significantly more captures at $16^{\circ} \mathrm{C}$ than at $10^{\circ} \mathrm{C}$, when shrimp were foraging at the low flounder density (Fig. 2a). Moreover, when shrimp were exposed to $10^{\circ} \mathrm{C}$, captures of flounder significantly increased at high density relative to low density (Fig. 2a,b).

Shrimp ingestion rates $(I)$ of flounder varied significantly with flounder size and temperature (Table 1, Fig. 2c,d). Approximately $60 \%$ fewer large flounder were consumed relative to small or medium-sized flounder. Increasing temperature from 10 to $16^{\circ} \mathrm{C}$ also resulted in a 2.3-fold increase in the number of flounder consumed by an individual shrimp during the observation period. Shrimp ingestion of flounder did not differ significantly across densities, and all of the interaction terms were insignificant (Table 1, Fig. 2c,d).

The proportion of encounters that resulted in a predatory attack (prey recognition, $R$ ) differed significantly with flounder size, density, and temperature (Table 1, Fig. 3a,b). Shrimp recognition of flounder as potential prey was 50 to $60 \%$ greater for large flounder relative to small and medium-sized fish. Prey recognition was also significantly greater at $16^{\circ} \mathrm{C}$ and the high flounder density (Fig. 3a,b).

The attack and capture success of shrimp $\left(S_{\mathrm{A}}\right.$ and $\left.S_{\mathrm{C}}\right)$ differed significantly with flounder size, but not with temperature or flounder density (Table 1, Fig. 3c-f). The proportion of shrimp attacks leading to a captured flounder decreased by 63 to $75 \%$ for large and medium fish relative to small flounder (Fig. 3c,d). Similarly, the proportion of captures resulting in shrimp consuming a flounder significantly decreased with increasing flounder size $\left(S_{\mathrm{C}}=0.96 \pm 0.02\right.$ for small, $0.50 \pm 0.07$ for 
a

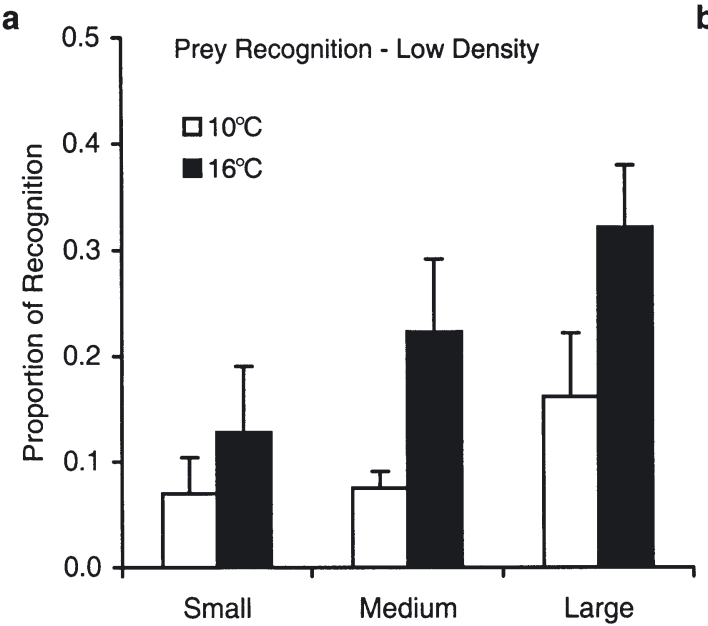

c

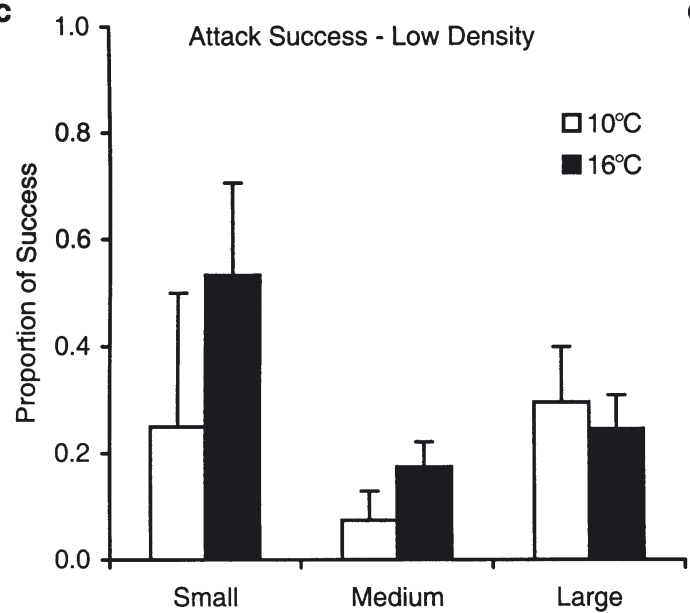

b

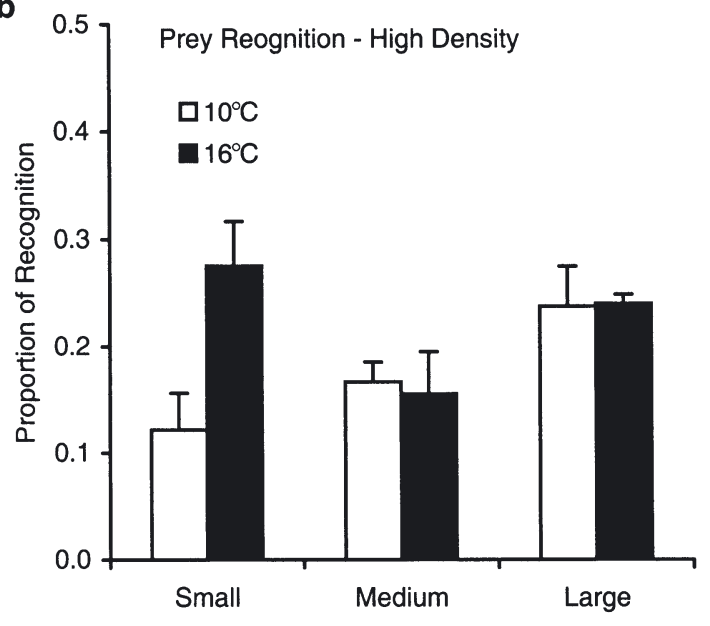

d

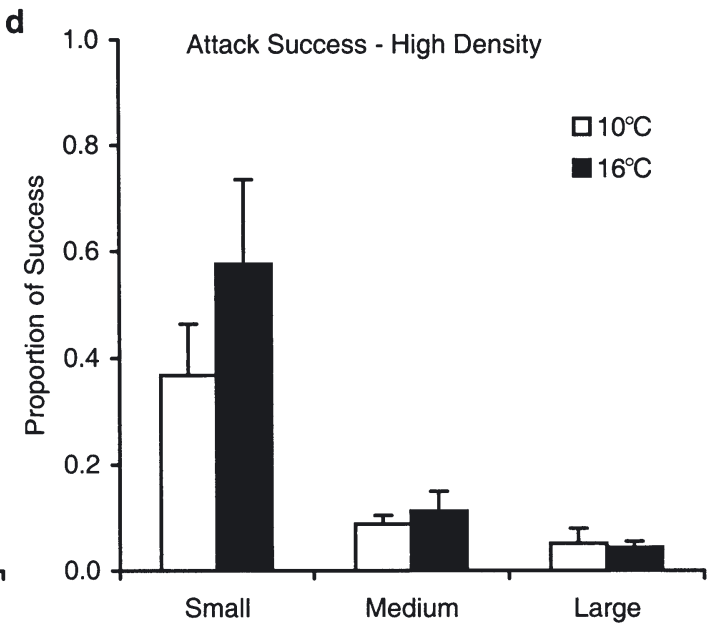

f

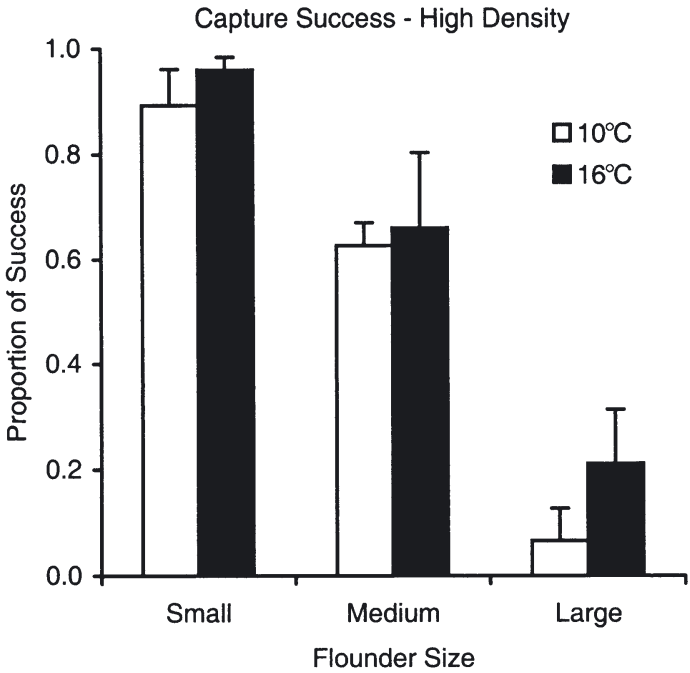

Fig. 3. Crangon septemspinosa predation on Pseudopleuronectes americanus. Prey recognition $\left(R_{i}\right.$ proportion of encounters resulting in attack) $(\mathrm{a}, \mathrm{b})$, attack success $\left(S_{\mathrm{A}}\right.$; proportion of attacks resulting in capture) $(\mathrm{c}, \mathrm{d})$, and capture success $\left(S_{\mathrm{C}}\right.$ proportion captures resulting in ingestion) $(\mathrm{e}, \mathrm{f})$ of shrimp preying on post-settlement winter flounder as a function of flounder size $($ small $=8$ to $12 \mathrm{~mm}$, medium $=13$ to $17 \mathrm{~mm}$, and large $=18$ to $22 \mathrm{~mm})$, temperature $\left(10^{\circ} \mathrm{C}=\right.$ white bars, $16^{\circ} \mathrm{C}=$ black bars $)$ and flounder density (low density $=2$ fish per tank, high density $=10$ fish per tank). Values are means $( \pm \mathrm{SE})$. See Table 1 for significant levels 

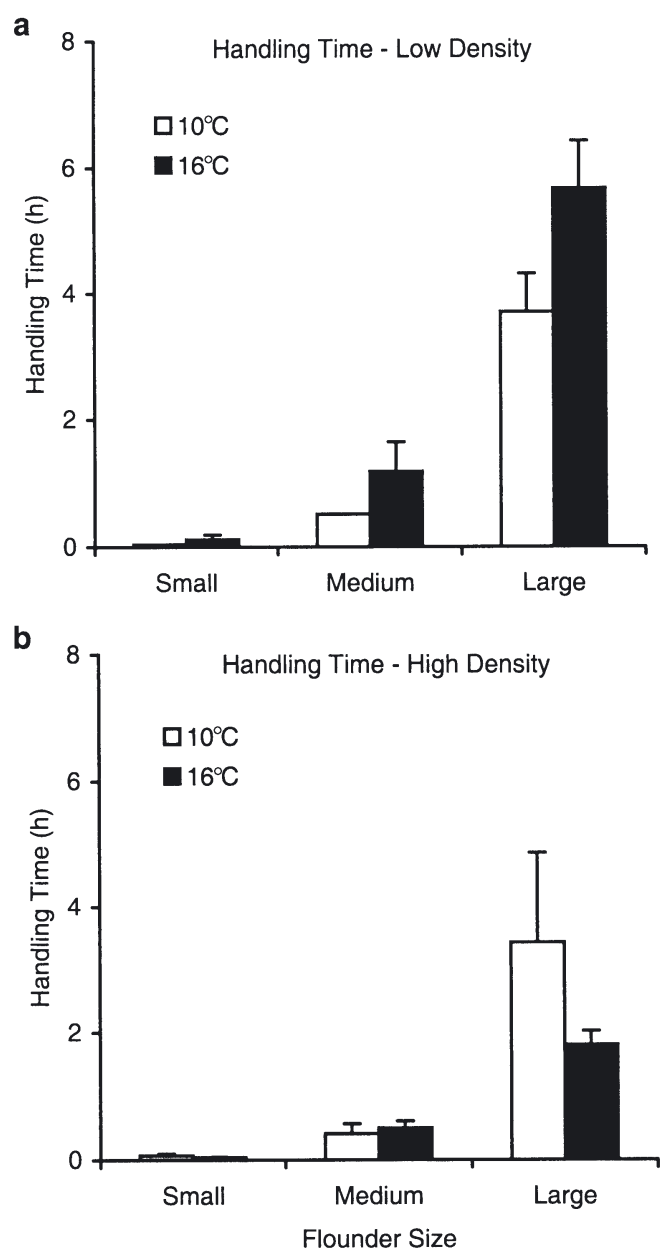

Fig. 4. Crangon septemspinosa predation on Pseudopleuronectes americanus. Observed handling time $\left(T_{\mathrm{h}} \mathrm{h}\right)$ of shrimp preying on post-settlement winter flounder as a function of flounder size (small $=8$ to $12 \mathrm{~mm}$, medium $=13$ to $17 \mathrm{~mm}$, and large $=18$ to $22 \mathrm{~mm})$, temperature $\left(10^{\circ} \mathrm{C}=\right.$ white bars, $16^{\circ} \mathrm{C}=$ black bars) and flounder density (low density $=$ 2 fish per tank and high density $=10$ fish per tank). Values are means $( \pm \mathrm{SE})$. See Table 1 for significant levels

medium, and $0.10 \pm 0.04$ for large flounder) (Fig. 3e,f) The latter estimate is also considered the flounder's escape capability. Accordingly, once a shrimp had seized and maintained the initial control of a flounder prey (defined as C), 50 and $90 \%$ of the predation attempts failed for medium and large flounder, respectively, whereas small flounder only had a $4 \%$ chance of escape.

The mean handling time $\left(T_{\mathrm{h}}\right)$ of an individual sand shrimp - initiated by encountering a flounder, followed by the attack, capture, and ingestion of the prey, and completed once searching by the predator resumed-differed significantly with flounder size and density (Table 1, Fig. 4). Shrimp handling time of flounder significantly increased with increasing prey size $\left(T_{\mathrm{h}}=0.06 \pm 0.03 \mathrm{~h}\right.$ for small, $0.54 \pm 0.18 \mathrm{~h}$ for medium, and $2.91 \pm 0.75 \mathrm{~h}$ for large flounder) (Fig. 4). Moreover, high temperature at low flounder density resulted in the significant increase in shrimp handling time (Fig. 4). The interaction term between flounder size and density was also significant, precluding contrasts across both size and density main effects (Table 1). The interaction effect between flounder size and density was caused by an insignificant density effect on the handling time of small and medium flounder size-classes (Fig. 4). Conversely, the handling time of large flounder was significantly lower at high flounder density than at low density (Fig. 4).

\section{Predation sequence, susceptibility, and vulnerability}

Multiple linear regression analysis indicated that shrimp encounters $\left(E^{\prime}\right)$ with flounder significantly increased with increasing fish size and density (Table 2). Logistic regression analysis of the remaining components of the predation sequence (i.e. conditional probabilities) indicated that increasing flounder size, density, and temperature significantly increased the probability of a fish being attacked

Table 2. Crangon septemspinosa predation on Pseudopleuronectes americanus. Summary statistics for multiple linear regression on encounters and logistic regression of the conditional probabilities of attacks, captures, and ingestion of shrimp preying on post-settlement winter flounder. $E^{\prime}$ : encounters; $P_{\mathrm{A}}$ : attack probability; $P_{\mathrm{C}}$ : capture probability; $P_{\mathrm{I}}$ : ingestion probability

\begin{tabular}{|lcc|}
\hline & Parameter estimate (SE) & $\mathrm{p}$ \\
\hline $\boldsymbol{E}^{\prime}$ & & \\
Intercept & $-40.7883(13.5179)$ & $<0.005$ \\
Size & $2.6545(0.5713)$ & $<0.0001$ \\
Density & $3.6395(0.5575)$ & $<0.0001$ \\
Temperature & $0.0414(0.7586)$ & 0.9566 \\
$\boldsymbol{P}_{\mathbf{A}}$ & \\
Intercept & $-6.5718(0.7155)$ & $<0.0001$ \\
Size & $0.1102(0.0177)$ & $<0.0001$ \\
Density & $0.0447(0.0095)$ & $<0.0001$ \\
Temperature & $0.2268(0.0425)$ & $<0.0001$ \\
Density $\times$ Temperature & $-0.0031(0.0007)$ & $<0.0001$ \\
$\boldsymbol{P}_{\mathbf{C}}$ & \\
Intercept & $-1.4068(1.4059)$ & 0.3170 \\
Size & $0.0031(0.0533)$ & 0.9541 \\
Density & $-0.0131(0.0059)$ & $<0.05$ \\
Temperature & $-0.0229(0.0646)$ & 0.7225 \\
$\boldsymbol{P}_{\mathbf{I}}$ & \\
Intercept & & \\
Size & $6.9233(4.3874)$ & 0.1146 \\
Density & $-0.5270(0.1686)$ & $<0.005$ \\
Temperature & $0.0088(0.0176)$ & 0.6164 \\
& $0.0528(0.1942)$ & 0.7857 \\
\hline
\end{tabular}


following a predatory encounter $\left(P_{\mathrm{A}}\right)$. Conversely, temperature and flounder size were not significant in determining the probability of capture $\left(P_{\mathrm{C}}\right)$, whereas decreasing flounder density resulted in the significant increase in $P_{\mathrm{C}}$ (Table 2). The probability of a flounder being ingested following a shrimp capture $\left(P_{\mathrm{I}}\right)$ decreased significantly with increasing fish size, and was independent of flounder density and temperature (Table 2). Statistically significant interaction effects were incorporated into regression analyses. Accordingly, the density-temperature interaction term was significant and therefore included in the logistic regression model of $P_{\mathrm{A}}$ (Table 2). The interaction terms for the remaining multiple and logistic regressions were insignificant, and were excluded from the models.
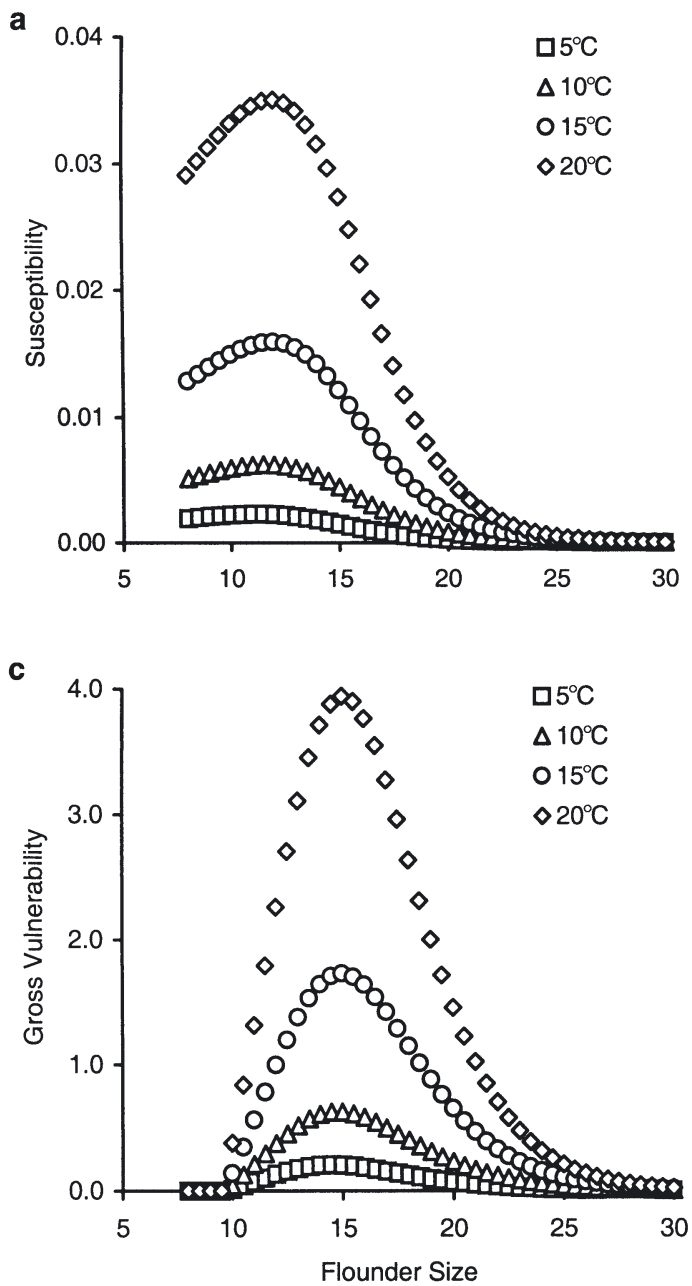

The product of the conditional probabilities of the predation sequence defines the flounder's susceptibility $(S)$ to shrimp predation, and was derived from the parameter estimates of the logistic regression analysis (Eqs. $2 \& 3$, Table 2). The susceptibility of flounder was maximal at fish sizes between 11 and $12 \mathrm{~mm}$ TL. Susceptibility then decreased with increasing fish size until flounder attained a complete refuge from shrimp predation at sizes $>25 \mathrm{~mm}$ TL (Fig. 5a,b). Temperature had a noticeable effect on the susceptible response curve, whereby increasing temperature increased the overall susceptibility of flounder to shrimp predation (prey density fixed at 4 flounder $\mathrm{m}^{-2}$ ) (Fig. 5a). The rate of increase in flounder susceptibility at higher temperatures, however, was not constant across flounder size. Increasing temperature resulted in a disproportionate
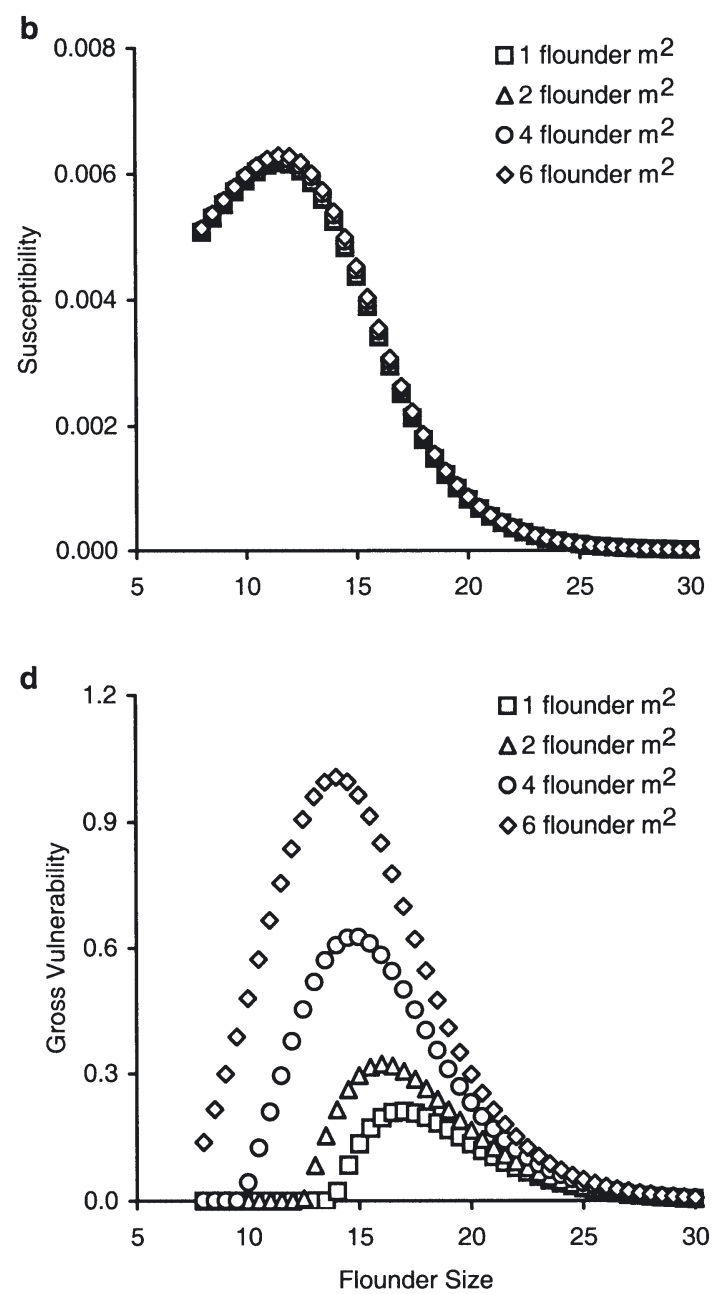

Fig. 5. Crangon septemspinosa predation on Pseudopleuronectes americanus. Winter flounder (8 to $30 \mathrm{~mm}$ total length [TL]) susceptibility $(\mathrm{a}, \mathrm{b})$ and gross vulnerability (no. flounder eaten shrimp $\left.\mathrm{p}^{-1} \mathrm{~m}^{-2} \mathrm{~d}^{-1}\right)(\mathrm{c}, \mathrm{d})$ to shrimp predation simulated across varying temperatures $\left(5\right.$ to $20^{\circ} \mathrm{C}$ ) and flounder densities ( 1 to 6 flounder $\mathrm{m}^{-2}$ ). Temperature-dependent susceptibility and vulnerability $(\mathrm{a}, \mathrm{c})$ were calculated at a constant prey density of 4 flounder $\mathrm{m}^{-2}$. Density-dependent susceptibility and vulnerability $(\mathrm{b}, \mathrm{d})$ were calculated at a constant temperature of $10^{\circ} \mathrm{C}$ 
increase in the susceptibility of medium-sized flounder to shrimp predation, such that the susceptibility response curve was profoundly dome-shaped at the highest temperatures $\left(15\right.$ and $\left.20^{\circ} \mathrm{C}\right)$. For example, at $5^{\circ} \mathrm{C}$, the maximum susceptibility of flounder to shrimp predation (max. $S$ at $5^{\circ} \mathrm{C}=0.0023$ ) occurred shortly after flounder settlement, when fish measured $11.2 \mathrm{~mm} \mathrm{TL}$. At $20^{\circ} \mathrm{C}$, the susceptibility of recently settled flounder (11.2 mm TL) increased to 0.0347 , but the maximum $S$ at this elevated temperature (max. $S$ at $20^{\circ} \mathrm{C}=0.0350$ ) occurred for flounder measuring $11.9 \mathrm{~mm}$ TL (Fig. 5a). At constant water temperature $\left(10^{\circ} \mathrm{C}\right)$, variations in flounder density ( 1 to 6 flounder $\mathrm{m}^{-2}$ ) did not have a marked effect on the sizedependent susceptibility of flounder to shrimp predation (Fig. 5b).

The gross vulnerability of flounder to shrimp predation $\left(G_{\mathrm{V}}\right)$ was dome-shaped across all simulated temperatures when analyzed graphically with respect to prey size (prey density fixed at 4 flounder $\mathrm{m}^{-2}$ ) (Fig. 5c). The number of flounder consumed and the convexity of the vulnerability response curve, however, increased substantially with increasing temperature (Fig. $5 \mathrm{c}$ ). The peak consumption rate of an individual shrimp increased 18.8 -fold, with an increase in temperature from 5 to $20^{\circ} \mathrm{C}(0.21$ and 3.94 flounder eaten shrimp ${ }^{-1} \mathrm{~m}^{-2} \mathrm{~d}^{-1}$, respectively). Similar to sus-

Table 3. Crangon septemspinosa predation on Pseudopleuronectes americanus. Summary statistics for ANOVA of the effects of flounder size (small $=8$ to $12 \mathrm{~mm}$, medium $=13$ to $17 \mathrm{~mm}$, and large $=18$ to $22 \mathrm{~mm}$ ), flounder density ( 2 and 10 fish per tank) and temperature $\left(10\right.$ and $\left.16^{\circ} \mathrm{C}\right)$ on observed shrimp gross and net caloric ingestion rates (cal eaten shrimp ${ }^{-1} 8 \mathrm{~h}^{-1}$ )

\begin{tabular}{|ccc|}
\hline Source & Gross caloric intake & Net caloric intake \\
\hline Density & & \\
$F($ df $)$ & $21.54(1)$ & $22.27(1)$ \\
$\mathrm{p}$ & $<0.0001$ & $<0.0001$ \\
Size & & \\
$F(\mathrm{df})$ & $5.36(2)$ & $5.34(2)$ \\
$\mathrm{p}$ & $<0.01$ & $<0.01$ \\
Density $\times$ Size & & \\
$F(\mathrm{df})$ & $2.97(2)$ & $3.03(2)$ \\
$\mathrm{p}$ & 0.0599 & 0.0561 \\
Temperature & & \\
$F(\mathrm{df})$ & $3.72(1)$ & $1.25(1)$ \\
$\mathrm{p}$ & 0.0589 & 0.2691 \\
Density $\times$ Temperature & \\
$F(\mathrm{df})$ & $0.91(1)$ & $0.94(1)$ \\
$\mathrm{p}$ & 0.3441 & 0.3353 \\
Size $\times$ Temperature & & \\
$F(\mathrm{df})$ & $2.00(2)$ & $1.99(2)$ \\
$\mathrm{p}$ & 0.1452 & 0.1463 \\
Density $\times$ Size $\times$ Temperature & \\
$F(\mathrm{df})$ & $2.55(2)$ & $2.67(2)$ \\
$\mathrm{p}$ & 0.0871 & 0.0786 \\
\hline
\end{tabular}

ceptibility, increasing temperature resulted in the disproportionate increase in gross vulnerability of medium-sized flounder relative to smaller and larger individuals. An increase in temperature from 5 to $20^{\circ} \mathrm{C}$, for example, resulted in the maximum $G_{\mathrm{V}}$ of flounder to shift from a body size of 14.5 to $15.0 \mathrm{~mm}$ TL. At a constant temperature $\left(10^{\circ} \mathrm{C}\right)$, increasing flounder density increased the gross vulnerability to shrimp predation because of an increase in encounter rates (Fig. 5d). The maximum consumption rate of an individual shrimp increased 4.8-fold, with an increase in density from 1 to 6 flounder $\mathrm{m}^{-2}$ ( 0.21 and 1.01 flounder eaten shrimp ${ }^{-1} \mathrm{~m}^{-2} \mathrm{~d}^{-1}$, respectively). In contrast to temperature-effects on size-dependent predation, increasing flounder density resulted in the disproportionate increase in gross vulnerability of small-sized flounder relative to larger individuals. An increase in density from 1 to 6 flounder $\mathrm{m}^{-2}$, for example, resulted in the maximum $G_{\mathrm{V}}$ of flounder to shift from a body size of 16.9 to $14.0 \mathrm{~mm}$ TL (Fig. 5d).

\section{Gross and net caloric intake}

The gross caloric intake of shrimp was significantly greater when feeding on medium and large flounder as compared to the smaller individuals (Table 3, Fig. 6a,b). Averaged across temperature and flounder density treatments, an individual shrimp foraging on small flounder only consumed 4.8 calories during the observation period, whereas feeding on medium and large flounder resulted in the intake of 19.9 and $16.2 \mathrm{cal}$ shrimp ${ }^{-1} 8 \mathrm{~h}^{-1}$, respectively. The increase in flounder density resulted in a significant 5.1-fold increase in shrimp caloric ingestion rates (Table 3, Fig. 6a,b). Shrimp gross caloric intake increased $79 \%$ with increasing temperature from 10 to $16^{\circ} \mathrm{C}$, but this effect was insignificant $(p=0.0589)$ and all of the interaction terms were insignificant at the $p<0.05$ level (Table 3).

Shrimp net caloric ingestion of flounder differed significantly with fish size and density, but not with temperature (Table 3, Fig. 6c,d). Shrimp feeding on small flounder suffered a net loss in energy $(-0.33 \pm$ $0.93 \mathrm{cal} \mathrm{shrimp}^{-1} 8 \mathrm{~h}^{-1}$ ) due to metabolic costs associated with foraging. Conversely, due to the increased caloric content of larger prey, shrimp ingestion of medium and large flounder resulted in a net increase in energy intake $(+14.47 \pm 4.46$ and $+10.61 \pm 5.26 \mathrm{cal}$ shrimp ${ }^{-1} 8 \mathrm{~h}^{-1}$ for medium and large flounder, respectively). This net energetic gain occurred despite greater metabolic demands on shrimp resulting from the longer handling time of larger prey (Fig. 4). Irrespective of flounder size, shrimp foraging on low prey densities experienced a significant decrease in net 
a

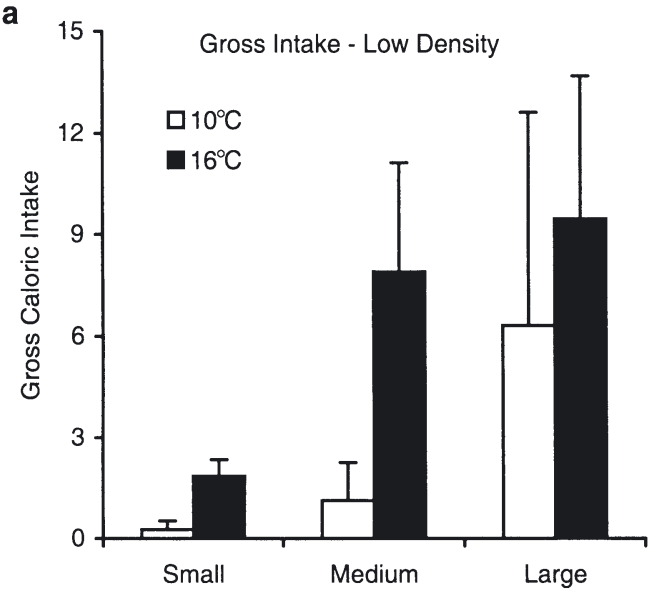

c

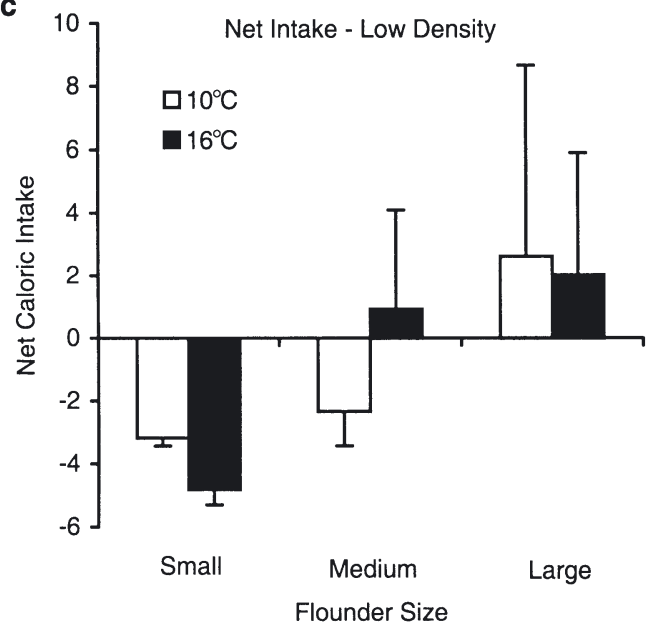

b

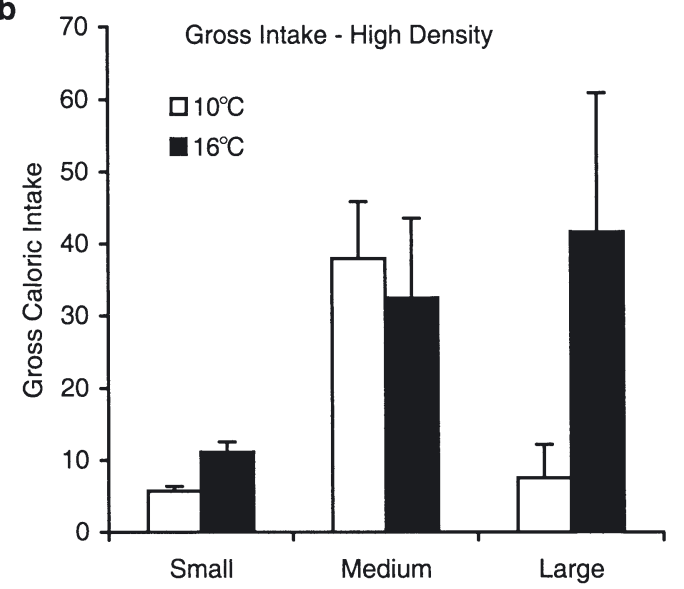

d

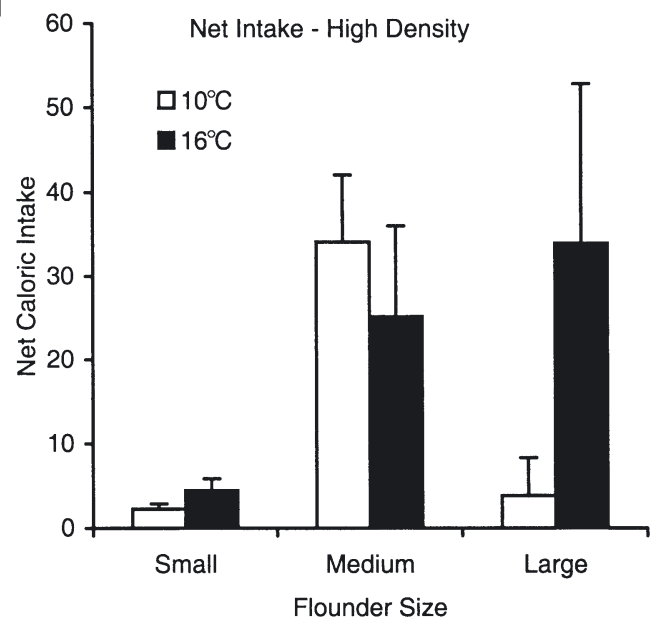

Fig. 6. Crangon septemspinosa predation on Pseudopleuronectes americanus. Gross caloric intake (cal eaten shrimp $\left.{ }^{-1} 8 \mathrm{~h}^{-1}\right)(\mathrm{a}, \mathrm{b})$ and net caloric intake (cal eaten shrimp $\left.{ }^{-1} 8 \mathrm{~h}^{-1}\right)(\mathrm{c}, \mathrm{d})$ of shrimp preying on post-settlement winter flounder as a function of flounder size (small $=8$ to $12 \mathrm{~mm}$, medium $=13$ to $17 \mathrm{~mm}$, and large $=18$ to $22 \mathrm{~mm}$ ), temperature $\left(10^{\circ} \mathrm{C}=\right.$ white bars, $16^{\circ} \mathrm{C}=$ black bars) and flounder density (low density $=2$ fish per tank, high density $=10$ fish per tank). Values are means $( \pm \mathrm{SE})$. See Table 3 for significant levels

caloric intake, whereby predators feeding on low flounder density suffered a net loss in energy $(-0.79 \pm$ $1.31 \mathrm{cal} \mathrm{shrimp}^{-1} 8 \mathrm{~h}^{-1}$ ), and shrimp feeding on high densities experienced a net energetic gain (17.29 \pm $4.43 \mathrm{cal} \mathrm{shrimp}^{-1} 8 \mathrm{~h}^{-1}$ ) (Table 3, Fig. 6c, d).

The predicted net intake of caloric energy of shrimp feeding on a range of flounder sizes followed a similar pattern to the theoretical maximum ingestion rates (Fig. 7). Both analyses suggest that net energetic gain increases at an accelerated rate with increasing flounder size, until reaching a peak value at flounder lengths of approximately 17.0 and $19.4 \mathrm{~mm}$ TL (predicted and theoretical maximum, respectively). Beyond the optimal prey size, the rate of caloric intake decreases abruptly with increasing flounder length. Discrepancies between the 2 analyses are apparent, however. Foremost, predicted caloric intake is substantially lower than the theoretical maximum, there- fore suggesting that shrimp are (metabolically) inefficient predators of juvenile flounder. Specifically over the prey size range examined ( 8 to $22 \mathrm{~mm} \mathrm{TL}$ ), predicted caloric ingestion rates were only $11.1 \%$ of the theoretical maximum (predicted $=9.5 \mathrm{cal}$ eaten shrimp $^{-1} 8 \mathrm{~h}^{-1}$ and maximum $=85.6 \mathrm{cal}$ eaten shrimp ${ }^{-1}$ $8 \mathrm{~h}^{-1}$ ). The relative rate of increase in net caloric intake with initial increases in flounder size was greater for predicted values as compared to the theoretical maximum. Consequently, peak energetic gain occurred at a smaller flounder size (17.0 mm TL) for predicted values relative to the optimal prey size estimated for maximum caloric intake (19.4 mm TL). Moreover, shrimp feeding at a maximum rate experienced a net gain in energy over the entire range of flounder lengths. In contrast, the predicted net caloric intake of shrimp suggests that predators foraging on flounder smaller than $10.8 \mathrm{~mm}$ TL suffer a net loss in energy. 


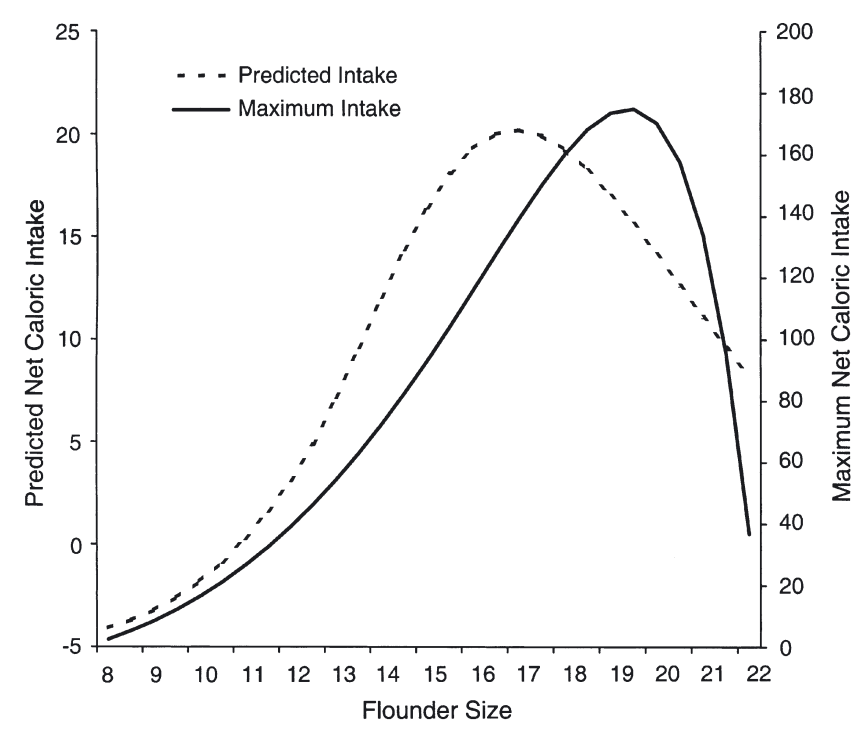

Fig. 7. Crangon septemspinosa predation on Pseudopleuronectes americanus. Observed net caloric intake (cal eaten shrimp ${ }^{-1} 8 \mathrm{~h}^{-1}$ ) (dashed line, primary $y$-axis) and theoretical maximum net caloric intake (cal eaten shrimp ${ }^{-1} 8 \mathrm{~h}^{-1}$ ) (solid line, secondary $y$-axis) of shrimp preying on post-settlement winter flounder (8 to 22 mmtotal length [TL])

\section{DISCUSSION}

The risk of death due to predation has been argued to decrease with increased prey size, by minimizing vulnerability to predators (bigger-is-better hypothesis, e.g. Miller et al. 1988). The generalization that being large-at-age confers a survival advantage, however, is mostly founded on laboratory experiments and conceptual models that analyze the probability of successful captures in isolation relative to the complete predation sequence. Because of the additional effect of prey size on the remaining components of the predation sequence, these previous studies fail to provide enough information to support the bigger-is-better hypothesis. Several investigators have cautioned that forecasting the survival of early-stage fish, strictly as a function of capture success, may lead to erroneous conclusions because of the added effect of sizedependent encounter rates on the predation outcome (Cowan \& Houde 1992, Litvak \& Leggett 1992, Cowan et al. 1996, Paradis et al. 1996). Fuiman (1989) determined that the gross vulnerability of Atlantic herring Clupea harengus larvae to predation from larger conspecifics was dome-shaped because of the competing effects of increased encounter rates (due to increased conspicuousness) and decreased capture probability (due to increased escape responsiveness) during larval development. Similarly, Pepin et al. (1992) proposed that the greater avoidance success of large capelin Mallotus villosus larvae from predation by sticklebacks
Gasterosteus aculeatus did not completely compensate for the increased visibility to predators. The contributions of these studies have led to the general consensus that the vulnerability of larval fish to predation follows a dome-shaped response when analyzed with respect to larvae size. However, little is known about the effects of size-selective processes on the predation of juvenile fish. The objective of this study was to quantify each component of the predation sequence, and describe how the product of these discrete components determines the gross vulnerability of juvenile winter flounder to shrimp predation. The key finding of this study was that smaller flounder do not incur the highest rate of predator-induced mortality. These results collaborate the previous findings of size-selective predation on larval fish, and therefore directly challenge the validity of the bigger-is-better hypothesis.

The dynamics underlying the size-dependent predation on flounder by Crangon septemspinosa are a function of the very different effect that prey body size has on the individual components of the predation sequence. The number of shrimp encounters $(E)$ with flounder increased nearly 4 -fold with increasing fish body size, and was attributed to several size-related properties of flounder. Larger flounder exhibit greater swimming speeds and increased conspicuousness (morphological and behavioral; Fuiman 1989) relative to smaller conspecifics. Increased flounder body size generally results in greater metabolic rates (Rose et al. 1996). This increases the search ambit of flounder because the fish are physiologically required to increase foraging activity to meet greater bioenergetic demands (Bailey \& Houde 1989). Increasing flounder size from 10 to $20 \mathrm{~mm}$ total length (TL), for example, is estimated to increase the relative search area of juveniles from 0.75 to $5.25 \mathrm{~m}^{2} \mathrm{~d}^{-1}$ (Rose et al. 1996). The greater activity of larger flounder is a behavioral change that increases the conspicuousness of the fish (Fuiman 1989, Fuiman \& Magurran 1994), and likely elicits a feeding response in predatory shrimp. Shrimp rely on several different sensory systems, including mechano- and chemoreception, for the detection of available prey (Wilcox \& Jeffries 1974). Increased activity of larger flounder is likely to displace greater volumes of water, which eventually increases the tactile and chemical stimuli recognized by sand shrimp. Morphological changes with increasing body size are also likely to increase the conspicuousness of flounder to potential predators (Fuiman 1989). Juvenile flounder become more visible with increasing size because of the larger body and the subsequent development of dense pigmentation. Increased visibility could increase the reactive distance of predatory shrimp, and thus act as a mechanism affecting shrimp encounter rates with flounder as a function of fish size. 
Optimal foraging theory predicts that the probability of attack following an encounter is dependent upon predators choosing prey that maximize their net energetic gain (Stephens \& Krebs 1986). Predators may therefore selectively target larger prey because they possess higher caloric value. Increased metabolic costs associated with pursuing, attacking, capturing, and handling larger prey, however, may decrease their net profitability, and therefore negate an increase in the predator's gross energetic gain (i.e. the rate of net energy intake decreases). Therefore, for a given-sized predator, there is an expected optimum prey size that yields the greatest energetic gain by minimizing the ratio between costs and benefits. Empirical estimates of shrimp ingestion rates, converted to units of calories, revealed that predation on medium and large flounder yielded a significantly greater amount of energy relative to predation on smaller individuals. In fact, a diet consisting of only small flounder (8 to $12 \mathrm{~mm} \mathrm{TL}$ ) resulted in a net loss of calories $\left(-0.33 \mathrm{cal} \mathrm{shrimp}^{-1}\right.$ $8 \mathrm{~h}^{-1}$ ). Adult shrimp (50 $\mathrm{mm} \mathrm{TL}$ ) received the greatest rate of net energetic gain when preying on flounder that were $17.0 \mathrm{~mm}$ TL. Below this optimal size, the net energy intake of shrimp decreased because of the lower caloric content of smaller flounder. Above the optimal flounder size, and despite the greater caloric content of larger prey, the increased metabolic demands associated with foraging on large flounder resulted in a decrease in shrimp net-energy gain. Moreover, the caloric content of flounder below the size of $10.8 \mathrm{~mm}$ TL does not provide shrimp with adequate energy to sustain their basic life processes, including metabolic activity and somatic and gonadal growth (Taylor \& Peck in press).

Another key finding of this research is that Crangon septemspinosa feeding on low densities of flounder, irrespective of prey size, suffered a net loss in calories $\left(-0.79\right.$ cal shrimp $\left.{ }^{-1} 8 \mathrm{~h}^{-1}\right)$. Thus, when densities of flounder are low $\left(<10\right.$ fish $\left.\mathrm{m}^{-2}\right)$, shrimp are physiologically required to supplement their diet with different and more abundant prey species. This switch-feeding behavior to alternative prey is a possible mechanism underlying the observed density-dependent predation of crangonid species feeding on flatfish (Van der Veer \& Bergman 1987, Wennhage 2002, Taylor \& Collie 2003b). C. crangon, for example, exhibits densitydependent predation on newly settled plaice Pleuronectes platessa in the presence of the alternative amphipod prey Corophium volutator (Wennhage 2002). The observed dependence of mortality on plaice density was attributed to switch-feeding behavior in $C$. crangon, and a change in the shrimp's feeding strategy as plaice density decreased below a threshold level.

Does Crangon septemspinosa forage selectively on juvenile flounder based on prey size? For any given encounter, selective predation is contingent upon the shrimp's ability to rank various-sized flounder according to their profitability, and to choose the most energetically profitable fish. Shrimp prey recognition $(R)$ and attack probability $\left(P_{\mathrm{A}}\right)$ of post-settlement flounder increased significantly at larger prey sizes. Thus, predators were more likely to initiate an attack on larger flounder following an encounter. The disturbance generated by an escaping small flounder, relative to larger individuals, may be insufficient to initiate an attack response from shrimp (i.e. small flounder go unnoticed by shrimp following a random encounter), thereby reducing the number of observed attacks on small fish. Shrimp may also implement a foraging strategy and decide on whether to attack a potential prey item based on its relative size and thus net profitability (i.e. small flounder are not attacked because of low profitability). It is important to note, however, that the experimental design in this study did not allow for an explicit analysis of foraging theory because predators were not offered a choice of varying-sized flounder, or alternative prey items, that differed in energy profitability. Thus, the possibility of shrimp intentionally selecting optimally sized flounder cannot be determined conclusively without the further analysis of predator choice. Moreover, C. septemspinosa size-selective predation on juvenile flounder must be analyzed in the context of the entire breadth of the shrimp's diet.

Subsequent to an attack by a predator, larger fish generally have a survival advantage relative to smaller individuals. Swimming speeds, burst swimming speeds, and responsiveness to predatory attacks, for example, typically increase with increasing fish size (Pittman et al. 1989, Blaxter \& Fuiman 1990, William \& Brown 1992), thus providing fish that are larger with a higher probability of escape given a predatory attack. The attack success of Crangon septemspinosa $\left(S_{\mathrm{A}}\right)$, or the proportion of attacks resulting in the capture of a flounder, decreased significantly with increasing flounder size, suggesting that larger individuals may have a more advanced initial responsiveness to predatory attacks. Similarly, the proportion of captures resulting in shrimp consuming a flounder $\left(S_{\mathrm{C}}\right)$, and the predator's ingestion probability $\left(P_{\mathrm{I}}\right)$, significantly decreased with increasing flounder size. This reflects the superior escape abilities of larger flounder, such that once a shrimp had seized and maintained the initial control of a flounder prey, 50 and $90 \%$ of the predation attempts failed for medium and large flounder, respectively, whereas small flounder only had a $4 \%$ chance of escape. Failed predation attempts on juvenile flounder periodically resulted in fin wounds. Injuries were nonlethal, however, and did not appear to render flounder more susceptible to subsequent shrimp attacks (Van der Veer \& Bergman 1987). These findings are consis- 
tent with other investigations examining the behavioral mechanisms underlying crangonid shrimp predation on post-settlement flatfish (Van der Veer \& Bergman 1987, Seikai et al. 1993, Gibson et al. 1995).

Juvenile flounder susceptibility $(S)$ to Crangon septemspinosa predation was maximal shortly after initial settlement, and decreased with increasing fish size. The pattern of decreasing susceptibility at larger body sizes has been observed in other studies of $C$. septemspinosa predation on post-settlement winter flounder (Witting \& Able 1995), as well as C. crangon predation on juvenile plaice (Van der Veer et al. 1987, 1991). A fundamental flaw in assuming that largeat-age fish have a survival advantage is that prey susceptibility is often recognized as the sole determinant of the outcome of a predation event, and sizedependent encounter rates are ignored (Fuiman \& Magurran 1994). Results from this study reaffirm the fact that each component of the predation sequence must be analyzed concurrently to fully understand the dynamics of a given predator-prey interaction. The contrasting effects of flounder size on the individual components of the predation sequence produced a gross vulnerability response curve that was domeshaped when analyzed graphically with respect to fish size. At the extremes of the dome-shaped vulnerability curve, shrimp consumed relatively few small and large flounder. Small flounder have a survival advantage because of their inconspicuousness to predatory shrimp. Small body sizes and associated decreases in activity (search ambit) cause a significant reduction in encounters with predators, thus minimizing the prey's gross vulnerability. Large flounder, despite frequent encounters with shrimp, also experience increased survival because of superior escape abilities and the prolonged handling time by predators. Conversely, medium-sized flounder suffer the highest rates of predator-induced mortality, and this was accentuated with increasing water temperature and decreasing prey density. These results challenge the validity of the bigger-is-better hypothesis, and suggest that being larger does not necessarily confer a survival advantage.

Small body sizes for flounder, relative to intermediate sizes, in certain situations can reduce instantaneous mortality. The immediate disadvantage imposed to larger flounder, however, may be compensated over the long term by these individuals having faster growth rates (Rice et al. 1993, Cowan et al. 1996). Hovenkamp (1992) determined that fast growth of larval plaice Pleuronectes platessa during the planktonic life stage resulted in greater survivorship and recruitment into coastal nurseries in the North Sea. Similarly, Meekan \& Fortier (1996) established a strong correlation between fast growth and the survival of larval Atlantic cod Gadus morhua on the Scotian Shelf. Taylor \& Collie (2003a) integrated the instantaneous vulnerability of juvenile winter flounder to Crangon septemspinosa predation over time to assess the effects of size-selective predation on recruitment. Consistent with the growth-mortality hypothesis (e.g. Miller et al. 1988), cohorts of faster growing flounder had a higher survival rate than slower-growing cohorts. The main benefit of accelerated growth was the decreased time that flounder were susceptible to shrimp predation (Taylor \& Collie 2003a). Consequently, the initial advantage of being small-at-age due to slow growth rates was negated once flounder grew into a more vulnerable size class and remained susceptible to predation for an extended length of time.

Post-metamorphic flatfish grow through a series of critical periods in which they are vulnerable to different predators (Fig. 8). This study examined the susceptibility and gross vulnerability of newly settled winter flounder to shrimp predation. Fairchild \& Howell (2000) implicated another decapod crustacean, the green crab Carcinus maenas, as a potential source of size-dependent mortality. The size at which flounder suffered maximum vulnerability to C. maenas predation was comparable to crangonid shrimp (11 to $20 \mathrm{~mm}$ $\mathrm{TL})$, yet crabs (<50 mm carapace width) successfully preyed upon juvenile flatfish up to $50 \mathrm{~mm}$ TL (Van der Veer \& Bergman 1987, Fairchild \& Howell 2000). Manderson et al. (1999) determined that striped searobin Prionotus evolans consume substantial numbers of winter flounder in vulnerable size classes (15 to $70 \mathrm{~mm}$ TL, peak mortality at 40 to $50 \mathrm{~mm} \mathrm{TL}$ ) in habitats where the 2 species co-occur. Summer flounder Paralichthys dentatus are also important predators of juvenile winter flounder in a prey size range of 20 to $90 \mathrm{~mm}$ TL (Manderson et al. 2000). Moreover, analysis of $P$. dentatus stomach contents revealed that summer flounder consume young-of-the-year flatfish of an average size of $32 \mathrm{~mm}$ TL (Manderson et al. 2000). Winter flounder otoliths have also been identified in the regurgitated pellets of the double-crested cormorant Phalacrocorax auritus (DNC 2003). The analysis of pellets of a congener species $P$. carbo indicated that flatfish constitute a large portion of the cormorant's diet (approx. $79 \%$ by mass) (Leopold et al. 1998). Assigning fish lengths based on recovered otoliths (plaice Pleuronectes platessa, dab Limanda limanda, flounder Platichthys flesus, and sole Solea solea), cormorants feed on fish that range in size between 50 and $300 \mathrm{~mm}$ TL, with peak consumption occurring at $80 \mathrm{~mm}$ TL (Leopold et al. 1998). These collective results indicate that 3 distinct predator fields exist for juvenile flounder during the first summer of life. While flounder suffer high mortality from decapod crustaceans during and shortly after initial settlement, 


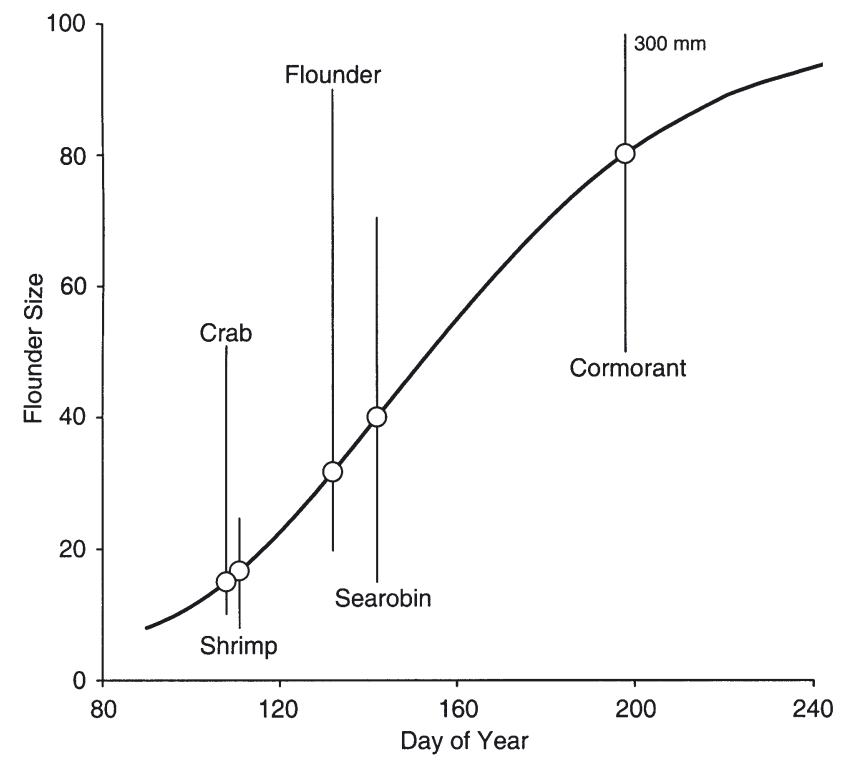

Fig. 8. Pseudopleuronectes americanus. Schematic diagram showing the body size ( $\mathrm{mm}$ total length [TL]) of post-settlement winter flounder during the first summer of life. Flounder lengths (thick line) were calculated from a temperature- and weight-specific bioenergetic model outlined in Rose et al. (1996). Vertical lines represent the size range at which flounder are vulnerable to a suite of predators: green crab Carcinus maenas, sand shrimp Crangon septemspinosa, summer flounder Paralichthys dentatus, striped searobin Prionotus evolans, and cormorant Phalacrocorax spp. Open circles represent the flounder body size at which maximum gross vulnerability occurs for a given predator

piscivorous fish and birds prey upon the later juvenile stages (Fig. 8).

Predator fields change throughout the course of flounder development primarily as a result of the relative body size of both predator prey (Pearre 1986) and the associated nutritional and feeding restrictions imposed on predators. For example, small flounder may yield insufficient energy to a predator and are therefore dismissed as a viable food resource. Conversely, flounder that are too large are inaccessible to certain predators because of physical limitations (i.e. prey size exceeds the gape size of the predator). Predator species also have different feeding strategies that dictate size-selective predation, whereby the primary sensory mechanisms used in prey selection shifts from a tactile to vision-oriented process with a change in predator field from crustaceans to piscivorous fish and birds (Bailey \& Houde 1989). Moreover, the spatial and temporal distribution of individuals within a designated predator field, relative to the vulnerability period of prey species, can have important consequences on size-dependent mortality of juvenile flatfish. For example, when the residence time, or spatial overlap, of predators exceeds the mortality window of flounder (e.g. decapod crustaceans), predation will become negatively size-dependent over time, and faster-growing flounder will incur a survival advantage (Van der Veer et al. 1997). Situations can occur, however, when the presence of predators does not coincide temporally with the full developmental period of the early juvenile life stage (Paradis et al. 1999). Transient predators (e.g. piscivorous fish) that feed during restricted periods of the mortality window can preclude the advantages of fast growth if larger flounder are selectively consumed during the brief predation period (Paradis et al. 1999). In summary, year-class strength and recruitment success of winter flounder is contingent upon the collective effects of all predator fields. It follows that the size-selective processes impacting the predator-induced mortality of juvenile flatfish cannot be ascertained from the analysis of a single species-specific predator-prey interaction. Conversely, to conclusively validate or refute a given recruitment hypothesis, future research should focus on the communal effects of predator fields on prey populations that vary in size-structure and age.

Acknowledgements. I am grateful to J. Collie (Graduate School of Oceanography, University of Rhode Island, Narragansett, RI) and 3 anonymous reviewers for scientific and editorial reviews, which greatly improved this manuscript. I also thank J. O'Connell and B. Morgan (Llennoco) for providing juvenile flounder, D. Danila (Environmental Laboratory, Millstone Power Station, Dominion Resources Services, Waterford, CT) for providing shrimp, and W. Macy (University of Rhode Island, Graduate School of Oceanography) for the allocation of laboratory space and equipment to conduct filming experiments. This research was partially funded by the Joshua MacMillan Graduate Fellowship in Fisheries Oceanography, Germaine and Francis Webb Graduate Fellowship in Oceanography, and URI/NOAA Cooperative Marine Education and Research (Award Number NA17FE2312).

\section{LITERATURE CITED}

Anderson JT (1988) A review of size dependent survival during pre-recruit stages of fishes in relation to recruitment. J Northwest Atl Fish Sci Soc 8:55-66

Bailey KM (1994) Predation on juvenile flatfish and recruitment variability. Neth J Sea Res 32(2):175-189

Bailey KM, Houde ED (1989) Predation on eggs and larvae of marine fishes and the recruitment problem. Adv Mar Biol 25:1-83

Bertram DF, Leggett WC (1994) Predation risk during the early life history periods of fishes: separating the effects of size and age. Mar Ecol Prog Ser 109:105-114

Blaxter JHS, Fuiman LA (1990) The role of the sensory systems of herring larvae in evading predatory fishes. J Mar Biol Assoc UK 70:413-427

Chambers RC, Leggett WC (1987) Size and age at metamorphosis in marine fishes: an analysis of laboratory-reared winter flounder (Pseudopleuronectes americanus) with a review of variation in other species. Can J Fish Aquat Sci 44:1936-1947 
Chambers RC, Leggett WC, Brown JA (1988) Variation in and among early life history traits of laboratory-reared winter flounder Pseudopleuronectes americanus. Mar Ecol Prog Ser 47:1-15

Cowan JH, Houde ED (1992) Size-dependent predation on marine fish larvae by ctenophores, scyphomedusae, and planktivorous fish. Fish Oceanogr 1:113-126

Cowan JH, Houde ED, Rose KA (1996) Size-dependent vulnerability of marine fish larvae to predation: an individual-based numerical experiment. ICES J Mar Sci 53: 23-37

Cowan JH, Rose KA, Houde ED (1997) Size-based foraging success and vulnerability to predation: selection of survivors in individual-based models of larval fish populations. In: Chambers RC, Trippel EA (eds) Early life history and recruitment in fish populations. Chapman \& Hall, London, p 357-386

Day RW, Quinn GP (1989) Comparisons of treatments after an analysis of variance in ecology. Ecol Monogr 59:433-463

DNC (Dominion Nuclear Connecticut) (2003) Monitoring the marine environment of Long Island Sound at Millstone Nuclear Power station. Annual Report 2002. Millstone Environmental Laboratory, Waterford, CT

Elliott JM, Davison W (1975) Energy equivalents of oxygen consumption in animal energetics. Oecologia 19:195-201

Fairchild EA, Howell WH (2000) Predator-prey size relationship between Pseudopleuronectes americanus and Carcinus maenas. J Sea Res 44:81-90

Fuiman LA (1989) Vulnerability of Atlantic herring larvae to predation by yearling herring. Mar Ecol Prog Ser 51: 291-299

Fuiman LA, Magurran AE (1994) Development of predator defences in fishes. Rev Fish Biol 4:145-183

Gibson RN, Yin MC, Robb L (1995) The behavioural basis of predator-prey size relationships between shrimp (Crangon crangon) and juvenile plaice (Pleuronectes platessa). J Mar Biol Assoc UK 75:337-349

Houde ED (1987) Fish life dynamics and recruitment variability. Am Fish Soc Symp 2:17-29

Hovenkamp F (1992) Growth-dependent mortality of larval plaice Pleuronectes platessa in the North Sea. Mar Ecol Prog Ser 82:95-101

Kitchell JF, Magnuson JJ, Neill WH (1977) Estimation of caloric content for fish biomass. Environ Biol Fish 2: 185-188

Leggett WC, DeBlois E (1994) Recruitment in marine fishes: is it regulated by starvation and predation in the egg and larval stages? Neth J Sea Res 32:119-134

Leopold MF, Van Damme CJG, Van der Veer, HW (1998) Diet of cormorants and the impact of cormorant predation on juvenile flatfish in the Dutch Wadden Sea. J Sea Res 40: 93-107

Litvak MK, Leggett WC (1992) Age and size-selective predation on larval fishes: the bigger-is-better hypothesis revisited. Mar Ecol Prog Ser 81:13-24

Lundvall D, Svanbäck R, Persson L, Byström P (1999) Sizedependent predation in piscivores: interactions between predator and prey avoidance abilities. Can J Fish Aquat Sci 56:1285-1292

Manderson JP, Phelan BA, Bejda AJ, Stehlik L, Stoner AW (1999) Predation by striped searobin (Prionotus evolans, Triglidae) on young-of-the-year winter flounder (Pseudopleuronectes americanus, Walbaum): examining prey size selection and prey choice using field observations and laboratory experiments. J Exp Mar Biol Ecol 242: 211-231

Manderson JP, Phelan BA, Stoner AW, Hilbert J (2000) Pre- dator-prey relations between age-1 + summer flounder (Paralichthys dentatus, Linnaeus) and age-0 winter flounder (Pseudopleuronectes americanus, Walbaum): predator diets, prey selection, and effects of sediments and macrophytes. J Exp Mar Biol Ecol 25:17-39

Meekan MG, Fortier L (1996) Selection for fast growth during the larval life of Atlantic cod Gadus morhua on the Scotian Shelf. Mar Ecol Prog Ser 137:25-37

Meise C, Collie JS, Widman J, Howell P (1999) Growth and mortality of juvenile winter flounder in two New England estuaries. Estuaries 22:297-303

Miller TJ, Crowder LB, Rice JA, Marschall EA (1988) Larval size and recruitment mechanisms in fishes: toward a conceptual framework. Can J Fish Aquat Sci 45:1657-1670

Paradis AR, Pepin P, Brown JA (1996) Vulnerability of fish eggs and larvae to predation: review of the influence of the relative size of prey and predator. Can J Fish Aquat Sci 53:1226-1235

Paradis AR, Pépin M, Pepin P (1999) Disentangling the effects of size-dependent encounter and susceptibility to predation with an individual-based model for fish larvae. Can J Fish Aquat Sci 56:1562-1575

Pearcy WG (1962) Ecology of an estuarine population of winter flounder, Pseudopleuronectes americanus (Walbaum), Parts I-IV. Bull Bingham Oceanogr Collect 18:1-78

Pearre S (1986) Ratio-based trophic niche breadths of fish, the Sheldon spectrum, and the size-efficiency hypothesis. Mar Ecol Prog Ser 27:299-314

Pepin P (1990) Predation and starvation of larval fish: a numerical experiment of size- and growth-dependent survival. Biol Oceanogr 6:23-44

Pepin P, Shears TH, de Lafontaine Y (1992) Significance of body size to the interaction between a larval fish (Mallotus villosus) and a vertebrate predator (Gasterosteus aculeatus). Mar Ecol Prog Ser 81:1-12

Pittman K, Skiftevik AB, Harboe T (1989) Effect of temperature on growth rates and organgenesis of halibut (Hippoglossus hippoglossus L.). Rapp P-V Réun Cons Int Explor Mer 191:421-430

Pittman K, Skiftevik AB, Berg L (1990) Morphological and behavioural development of halibut, Hippoglossus hippoglossus (L.) larvae. J Fish Biol 37:455-472

Price KSJ (1962) Biology of the sand shrimp, Crangon septemspinosa, in the shore zone of the Delaware Bay region. Chesapeake Sci 3:244-255

Rice JA, Miller JA, Rose KA, Crowder LB, Marshall EA, Trebitz AS, DeAngelis DL (1993) Growth rate variation and larval survival: inferences from an individual-based sizedependent predation model. Can J Fish Aquat Sci 50: 133-142

Rose KA, Tyler JA, Chambers RC, Klein-MacPhee G, Danila DJ (1996) Simulating winter flounder population dynamics using coupled individual-based young-of-the-year and age-structured adult models. Can J Fish Aquat Sci 53: 1071-1091

Schreiber AM, Specker JL (1999) Early larval development and metamorphosis in the summer flounder: changes in percent whole-body water content and effects of altered thyroid status. J Fish Biol 55:148-157

Schuurmans CJE (1995) The world heat budget: expected changes. In: Eisma D (ed) Climate change: impact on coastal habitation. Lewis Publishers, Boca Raton, FL, p $1-16$

Seikai T, Kinoshita I, Tanaka M (1993) Predation by crangonid shrimp on juvenile Japanese flounder under laboratory conditions. Nippon Suisan Gakkaishi 59(2):321-326

Shepherd JG, Cushing GH (1980) A mechanism for density 
dependent survival of larval fish as the basis of a stockrecruitment relationship. J Cons Perm Int Explor Mer 39: 160-167

Sogard SM, Able KW, Hagan SM (2001) Long-term assessment of settlement and growth of juvenile winter flounder (Pseudopleuronectes americanus) in New Jersey estuaries. J Sea Res 45:189-204

Stephens DW, Krebs JR (1986) Foraging theory. Princeton University Press, Princeton

Taylor DL, Collie JS (2003a) A temperature and size-dependent model of sand shrimp (Crangon septemspinosa) predation on juvenile winter flounder (Pseudopleuronectes americanus). Can J Fish Aquat Sci 60:1133-1148

Taylor DL, Collie JS (2003b) Effect of temperature on the functional response and foraging behavior of the sand shrimp Crangon septemspinosa preying on juvenile winter flounder Pseudopleuronectes americanus. Mar Ecol Prog Ser 263:217-234

Taylor DL, Peck MA (in press) Daily energy requirements and trophic positioning of the sand shrimp Crangon septemspinosa. Mar Biol

Van der Veer HW, Bergman MJN (1987) Predation by crustaceans on newly settled 0-group plaice Pleuronectes platessa populations in the western Wadden Sea. Mar Ecol Prog Ser 35:203-215

Van der Veer HW, Bergman MJN, Dapper R, Witte JIJ (1991)

Editorial responsibility: Otto Kinne (Editor),

Oldendorf/Luhe, Germany
Population dynamics of an intertidal 0-group flounder Platichthys flesus population in the western Dutch Wadden Sea. Mar Ecol Prog Ser 73:141-148

Van der Veer HW, Ellis T, Miller JM, Pihl L, Rijnsdorp AD (1997) Size-selective predation on juvenile North Sea flatfish and possible implications for recruitment. In: Chambers RC, Trippel EA (eds) Early life history and recruitment in fish populations. Chapman \& Hall, London, p 279-303

Ware DM (1975) Relation between egg size, growth and natural mortality of larval fish. J Fish Res Board Can 32: 2503-2512

Wennhage H (2002) Vulnerability of newly settled plaice (Pleuronectes platessa L.) to predation: effects of habitat structure and predator functional response. J Exp Mar Biol Ecol 269:129-145

Wilcox JR, Jeffries HP (1974) Feeding habits of the sand shrimp Crangon septemspinosa. Biol Bull 146:424-434

Williams PJ, Brown JA (1992) Developmental changes in the escape response of larval winter flounder Pleuronectes americanus from hatch through metamorphosis. Mar Ecol Prog Ser 88:185-193

Witting DA, Able KW (1995) Predation by sevenspine bay shrimp Crangon septemspinosa on winter flounder Pleuronectes americanus during settlement. Mar Ecol Prog Ser 123:23-31

Submitted: April 23, 2003; Accepted: September 7, 2003 Proofs received from author(s): November 24, 2003 